\title{
Reconstituição da valva pulmonar e via de saída do ventrículo direito, com prótese bivalvular e prótese tubular valvada de tronco pulmonar de porco: estudo experimental e aplicação clínica
}

Miguel A. MALUF*, José L. VERDE** , João Carlos LEAL**, Roberto CATANI*, Herminio Vega GARCIA $\mathrm{Jr}^{*}{ }^{*}$, Rubens THEVENARD ${ }^{\star \star}$, Antonio C. CARVALHO*, José L. ANDRADE ${ }^{\star}$, José Carlos S. ANDRADE*, Domingo M. BRAILE**, Luiz Eduardo V. LEĀO*, Ênio BUFFOLO*

MALUF, M. A.; VERDE, J. L.; LEAL, J. C.; CATANI, R.; GARCIA Jr., H. V.; THEVENARD, R.; CARVALHO, A. C.; ANDRADE, J. L.; ANDRADE, J. C. S.; BRAILE, D. M.; LEĀO, L. E. V.; BUFFOLO, E. - Reconstruçāo da valva pulmonar e via de saída do ventrículo direito, com prótese bivalvular e prótese tubular valvada de tronco pulmonar de porco: estudo experimental e aplicaçāo clínica. Rev. Bras. Cir. Cardiovasc., 8(1):20-38, 1993.

RESUMO: A obstrução da via de saída do ventrículo direito (VSVD) tem gerado muita polêmica em torno da técnica da sua correção cirúrgica, sendo a reconstituição ainda motivo de controvérsias. Com essa finalidade, foram desenvolvidas duas próteses a partir do tronco pulmonar (TP) de porco: 1) a prótese bivalvular: poderia ser usada na correçāo da tétrade de Fallot associada a hipoplasia do anel pulmonar: 2) a prótese tubular valvada, possuindo a própria valva pulmonar: poderia ser empregada na correçāo de malformaçōes com descontínuidade entre o VD e TP. Estes dois tipos de próteses foram testados em modelo experimental. Seis ovelhas foram submetidas a implante de prótese bivalvular, com o auxílio da circulação extracorpórea (CEC), após ampla ressecçāo do infundíbulo pulmonar, incluindo duas válvulas da valva pulmonar, procurando-se, com isto, imitar a reconstituiçāo empregada no Fallot. O implante da prótese tubular valvada foi realizado em 12 ovelhas, sem o auxílio da CEC, mediante pinçamento tangencial do infundíbulo e TP, permitindo o desvio do fluxo sangüíneo através do conduto, após ligadura do TP. A prótese bivalvular implantada foi avaliada mediante parâmetros hemodinâmicos e ecocardiográficos na fase intra-operatória, conferindo desempenho satisfatório (insuficiência pulmonar discreta ou ausente e gradientes VD-TP menores de $10 \mathrm{mmHg}$ ). A seguir, os animais foram sacrificados. O desempenho da prótese tubular valvada foi avaliada na fase intra-operatória com medidas hemodinâmicas, mostrando gradientes acima de $10 \mathrm{mmHg}$ em apenas 3 casos. Sete ovelhas tiveram controle ecocardiográfico com 99 a 135 dias de evolução, registrando gradientes de $9,85 \mathrm{mmHg}$ a $49 \mathrm{mmHg}$ (média 19,7). Quatro casos foram submetidos a estudo hemodinâmico no $6^{\circ}$ mês de evolução, registrando discreto aumento do gradiente (média 22,3); a seguir os animais foram sacrificados e encaminhados para estudo anatomopatológico. A aplicaçāo clínica da prótese bivalvular foi realizada em 3 pacientes portadores de t. de Fallot associada a hipoplasia do anel pulmonar (2 casos) e agenesia da valva pulmonar ( 1 caso), com idades de 16, 2 e 7 anos. Após evoluçâo de 3 a 10 meses, os gradientes variaram entre $10 \mathrm{mmHg}$ e $20 \mathrm{mmHg}$ e discreta insuficiência pulmonar valvar ao estudo

Trabalho realizado na Escola Paulista de Medicina e no Instituto de Moléstias Cardiovasculares, Sâo José do Rio Preto, SP, Brasil.

* Da Escola Paulista de Medicina.

* Do Instituto de Moléstias Cardiovasculares (Sảo José do Rio Preto).

Endereço para separatas: Miguel A. Maluf, Rua Napoleão de Barros $n^{\ominus} 715,3^{\circ}$ andar (Disciplina de Cirurgia Cardiovascular) 04024-002, Sảo Paulo, SP, Brasil. 
MALUF, M. A.; VERDE, J. L.; LEAL, J. C.; CATANI, R.; GARCIA Jr., H. V.; THEVENARD, R.; CARVALHO, A. C.; ANDRADE, J. L.; ANDRADE, J. C. S.; BRAILE, D. M.; LEĀO, L. E. V.; BUFFOLO, E. - Reconstruçāo da valva pulmonar e via de saída do ventrículo direito, com prótese bivalvular e prótese tubular valvada de tronco pulmonar de porco: estudo experimental e aplicação clínica. Rev. Bras. Cir. Cardiovasc., 8(1):20-38, 1993.

\begin{abstract}
ecodopplercardiográfico. A prótese tubular valvar foi implantada em 2 pacientes portadores de atresia pulmonar associada a comunicação interventricular (CIV) e outro a transposição corrigida das grandes artérias (TCGA) associada a CIV e estenose subpulmonar, com idades de 10 e 6 anos, respectivamente. Após evoluçäo de 5 a 12 meses, foram detectados suficiência da valva pulmonar, gradientes entre $15 \mathrm{mmHg}$ e 18 $\mathrm{mmHg}$, sem sinais de calcificação. Apesar de se considerar aceitáveis os resultados desta experiência, a ampliaçāo das indicaçōes deverá ser feita com cautela, até o melhor conhecimento da resistência da prótese a calcificação, infecçāo, obstruçāo e rotura.
\end{abstract}

DESCRITORES: valva pulmonar, cirurgia; próteses valvulares cardíacas, biológicas, cirurgia.

\section{INTRODUÇĀO}

O desenvolvimento de técnicas operatórias corretivas nas malformaçōes cardíacas com hipofluxo pulmonar propiciou substancial melhora no prognóstico de crianças portadoras de anomalias como a tétrade de Fallot. A operaçāo é atualmente realizada com baixa mortalidade e resultado tardio muito satisfatório.

Desde as primeiras operaçōes, observou-se que, em alguns pacientes, era necessária a ampliação da via de saída do ventrículo direito, para alívio completo da estenose pulmonar. Surgia, assim, a necessidade de uma prótese para ampliação da via de saída do ventrículo direito (VSVD). LILLEHEI et alii $^{31}$, nos relatos pioneiros da correçāo da tétrade de Fallot, sugeriram a secçāo e o alargamento do anel pulmonar. O posicionamento do retalho para ampliaçāo da via de saída do ventrículo direito e tronco pulmonar ocasionava a insuficiência pulmonar valvar (IPV).

Mais recentemente, a importância clínica da IPV após a ampliaçāo do anel e tronco pulmonar hipoplásicos torna-se cada vez mais evidente, à medida em que se conhece melhor o resultado da operaçāo, a médio e longo prazos $13,17,28,52,56$.

PACIFICO et alii ${ }^{39}$ padronizaram a estratégia para a ampliaçāo do anel pulmonar, baseados no nomograma de ROWLATT et alii ${ }^{44}$, que relaciona a medida do anel pulmonar com peso e superfície corpórea de crianças normais, possibilitando, assim, a uniformização do procedimento.

Se a indicaçāo da ampliaçāo transvalvar pulmonar ficou mais clara, a escolha do material foi menos estudada. Assim, o pericárdio autógeno foi utilizado por LILLEHEI et alii ${ }^{31}$, SABISTON et alii ${ }^{45}$, HORIUCHI et alii ${ }^{23}$, entre outros; a dura-máter conservada em glicerina por ZERBINI ${ }^{57}$, VERGINELLI et alii ${ }^{54}$, o woven Dacron pela maioria dos autores $10,28,29$. Finalmente, o pericárdio bovino tratado em glutaraldeído foi preconizado por alguns autores, principalmente no nosso meio $12,25,35,53$.

A preocupação com a suficiência pulmonar valvar, quando da ampliaçāo da via de saída, pode ser apreciada com as contribuiçōes de MARCHAND ${ }^{34}$, WELDON et alii ${ }^{55}$, BINET et alii ${ }^{5}$, utilizando valva aórtica.

TRUSLER et alii ${ }^{52}$, em 1973, utilizaram enxerto de pericárdio autógeno com monoválvula, para a mesma finalidade. Tal enxerto teve adequado desempenho no pós-operatório imediato, perdendo, contudo, sua funçāo tardiamente, com retração e calcificação. Alternativa semelhante foi preconizada por IONESCU et alii ${ }^{25}$, utilizando enxerto de pericárdio bovino conservado, onde foi suturada monoválvula do mesmo tecido.

MARCHAND ${ }^{34}$, EGUCHI \& ASANO ${ }^{14}$ desenvolveram próteses bivalvulares, construídas com valva aórtica e pulmonar, procurando minimizar a IPV; os resultados nāo foram satisfatórios e o uso das próteses foi abandonado.

A estenose pulmonar, pelas numerosas variaçōes anatômicas, obrigou o uso de próteses em forma de retalho ou de tubo, para sua correçāo.

O interesse crescente pelo uso de prótese na reconstituiçāo da VSVD chamou a atenção daqueles que se empenharam na correção de anomalias congênitas com descontinuidade entre o veículo direito e a circulaçāo pulmonar, como no caso da atresia pulmonar (AP), sendo necessário o uso de uma prótese com forma de tubo.

Foi assim, após estudo experimental, que RASTELLI et alii ${ }^{41}$ implantaram, em pacientes, uma prótese tubular nāo valvulada de pericárdio autógeno, e ROSS \& SOMERVILLE ${ }^{42}$ empregaram, com sucesso, homoenxerto aórtico valvado.

No presente trabalho, utilizando tecnologia de preparo dos tecidos heterólogos, foram desenvolvidos dois modelos de próteses montadas a partir de dois segmentos de tronco pulmonar suíno, através de concepção original (MALUF ${ }^{32}$ ): 1) a prótese bivalvular, em forma de telha, teria sua aplicação clínica na tétrade de Fallot com hipoplasia do anel pulmonar, sendo possivel reconstituir a valva pulmonar aproveitando uma das válvulas nativas e, ao mesmo tempo, ampliar o tronco pulmonar e o infundíbulo do ventrículo direito; 2) a prótese tubular 
MALUF, M. A.; VERDE, J. L.; LEAL, J. C.; CATANI, R.; GARCIA Jr., H. V.; THEVENARD, R.; CARVALHO, A. C.; ANDRADE, J. L.; ANDRADE, J. C. S.; BRAILE, D. M.; LEĀO, L. E. V.; BUFFOLO, E. - Reconstruçāo da valva pulmonar e via de saída do ventrículo direito, com prótese bivalvular e prótese tubular valvada de tronco pulmonar de porco: estudo experimental e aplicaçāo clínica. Rev. Bras. Cir. Cardiovasc., 8(1):20-38, 1993.

valvada poderia ser empregada na reconstituiçäo da VSVD, em casos de descontinuidade entre o ventrículo e as artérias pulmonares. Também poderia ser útil em situaçōes onde fosse necessário desviar o fluxo sangüíneo para o pulmão, pelo risco de lesão de estruturas nobres próximas ao anel pulmonar (ramo interventricular anterior originandose da artéria coronária direita) no caso de ampliação convencional.

O objetivo do presente trabalho foi a avaliaçāo experimental e clínica da prótese bivalvular "em telha" e da tubular valvada na reconstituiçăo da via de saída do ventrículo direito, através da verificaçāo da suficiência pulmonar valvar e o grau de obstruçāo da via de saída do ventrículo direito, mediante estudo hemodinâmico e ecodopplercardiográfico no pós-operatório imediato e tardio, assim como a resistência do tronco pulmonar suíno preservado a calcificação, trombose, infecçāo e rotura valvar.

\section{MATERIAL E MÉTODOS}

\section{Confecçã̃o das Próteses}

Para o preparo do material biológico foram obedecidas várias etapas até a confecção da prótese. À retirada do coração suíno, segue-se o isolamento da valva pulmonar (VP) junto ao tronco pulmonar (TP), limpeza, curtimento e conservaçāo do tecido. Toda a seqüência foi descrita em minúcias por BRAILE 7

\section{Prótese Bivalvular}

Para a confecçāo da prótese bivalvular, partiuse de dois segmentos de TP, aproveitados em toda sua extensāo, desde o anel pulmonar até o início das artérias pulmonares. Preservou-se, em um segmento, a VP e, no outro, aproveitou-se a porçāo supravalvar. Usando os dilatadores de Hegar, foi realizada a mensuraçāo dos anéis valvares, sendo os enxertos classificados conforme seus diâmetros em milímetros.

Mediante uma incisāo longitudinal, praticada na porçāo côncava do enxerto, foi retirada uma fatia da parede junto com uma das válvulas da VP (Figura 1a). No segmento nāo valvado, foi retirada uma fatia de parede proporcional ao primeiro (Figura 1b). Finalmente, essas duas̀ estruturas foram juntadas pelos seus extremos proximais, superpondo-as numa extensāo de $3 \mathrm{~mm}$ a $5 \mathrm{~mm}$ e ligando-as mediante sutura contínua tipo chuleio, com pontos ancorados de Polipropileno 5-0. A sutura foi iniciada na face côncava do enxerto, acompanhando a borda de inserção das válvulas no anel fibromuscular. Sutura semelhante foi feita na face convexa.

$\mathrm{Na}$ avaliaçāo final, analisou-se, fundamentalmente, o aspecto geral, a integridade e mobilidade das válvulas, acabamento das linhas de sutura e, finalmente, a uniformidade da espessura da parede do enxerto (Figura 1c).

\section{Prótese Tubular Valvada}

Para a confecção da prótese tubular valvada, requereu-se, também, o uso de dois segmentos de
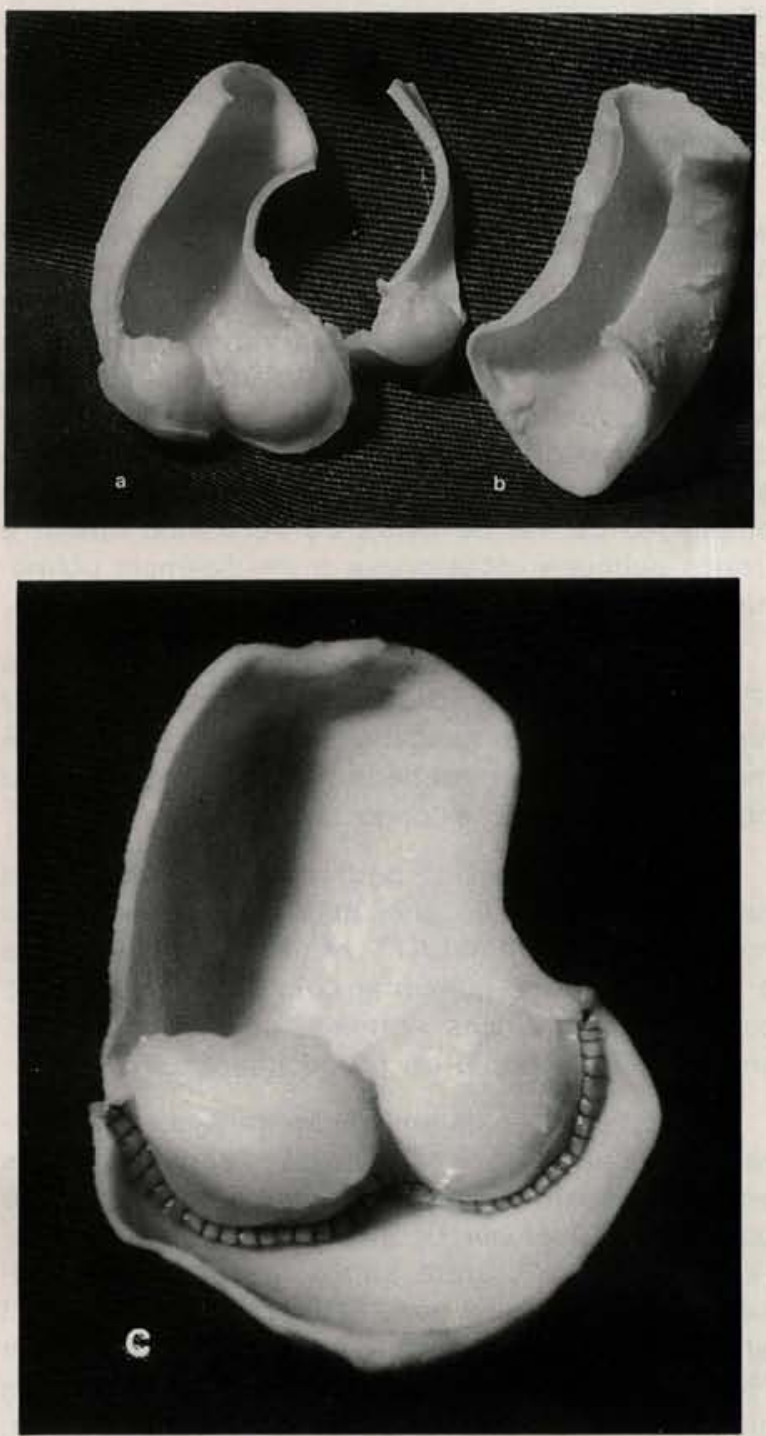

Fig. 1 - Montagem da prótese bivalvular. Abertura longitudinal e retirada de segmento de parede: a) com sua válvula; b) segmento proporcional da porção não valvulada; c) prótese montada (face interna). 
MALUF, M. A.; VERDE, J. L.; LEAL, J. C.; CATANI, R.; GARCIA Jr., H. V.; THEVENARD, R.; CARVALHO, A. C.; ANDRADE, J. L.; ANDRADE, J. C. S.; BRAILE, D. M.; LEĀO, L. E. V.; BUFFOLO, E. - Reconstrução da valva pulmonar e via de saída do ventrículo direito, com prótese bivalvular e prótese tubular valvada de tronco pulmonar de porco: estudo experimental e aplicação clínica. Rev. Bras. Cir. Cardiovasc., 8(1):20-38, 1993.

TP, um deles com a VP. A mensuração do anel valvar foi feita com o dilatador de Hegar, sendo necessário, para montagem adequada, que o diâmetro do segmento valvado fosse $3 \mathrm{~mm}$ a $4 \mathrm{~mm}$ menor do que o segmento nāo valvado.

O conduto foi construído por encaixe de dois segmentos do tronco pulmonar suíno, um deles incluindo a VP. Juntaram-se os dois segmentos pelo seu extremo proximal e, após everter a borda do segmento nāo valvado, efetuou-se a sutura interna em chuleio com fio de Polipropileno 5-0.

A seguir, foi desdobrada a borda evertida e efetuou-se a sutura externa, de maneira a ficar bem hemostática (Figura 2a).

O acabamento da prótese tubular valvada foi feito mediante a avaliaçāo da abertura e fechamento da VP, assim como espessura uniforme da parede. O teste de continência consistiu no pinçamento do extremo distal, enquanto foi injetada solução fisiológica com pressāo, pelo extremo proximal, no intuito de detectar algum vazamento.

As próteses foram submetidas a testes para controle de qualidade: 1) biológicos - exame histológico e histoquímico, tensão superficial crítica e controle bacteriológico; 2) físicos - teste de encolhimento, conforme as especificaçōes feitas por BRAILE 7 .

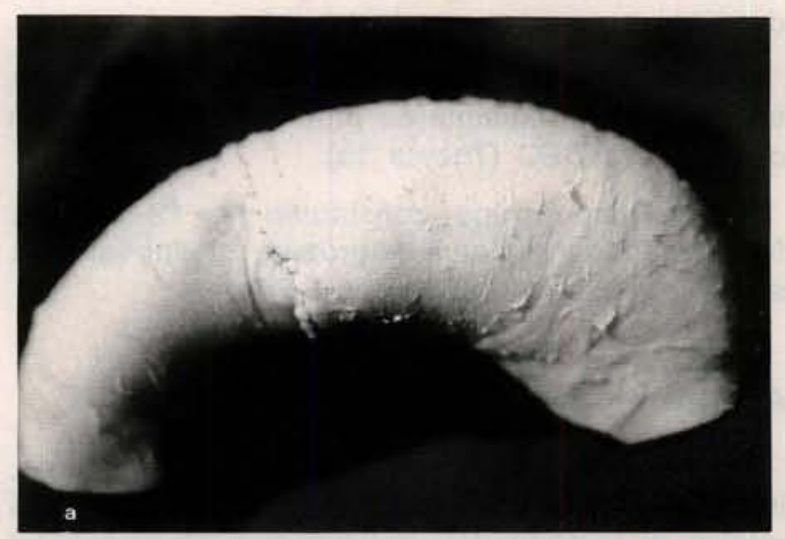

Fig. 2 - Montagem da prótese tubular valvada. a) encaixe dos seg. mentos da prótese após finalizada a sutura externa.

TABELA 1 A

RECONSTITUIÇĀO DA VALVA PULMONAR E VIA DE SAÍDA DO VENTRÍCULO DIREITO COM PRÓTESE BIVALVULAR PULMONAR SUINA, EM OVINOS

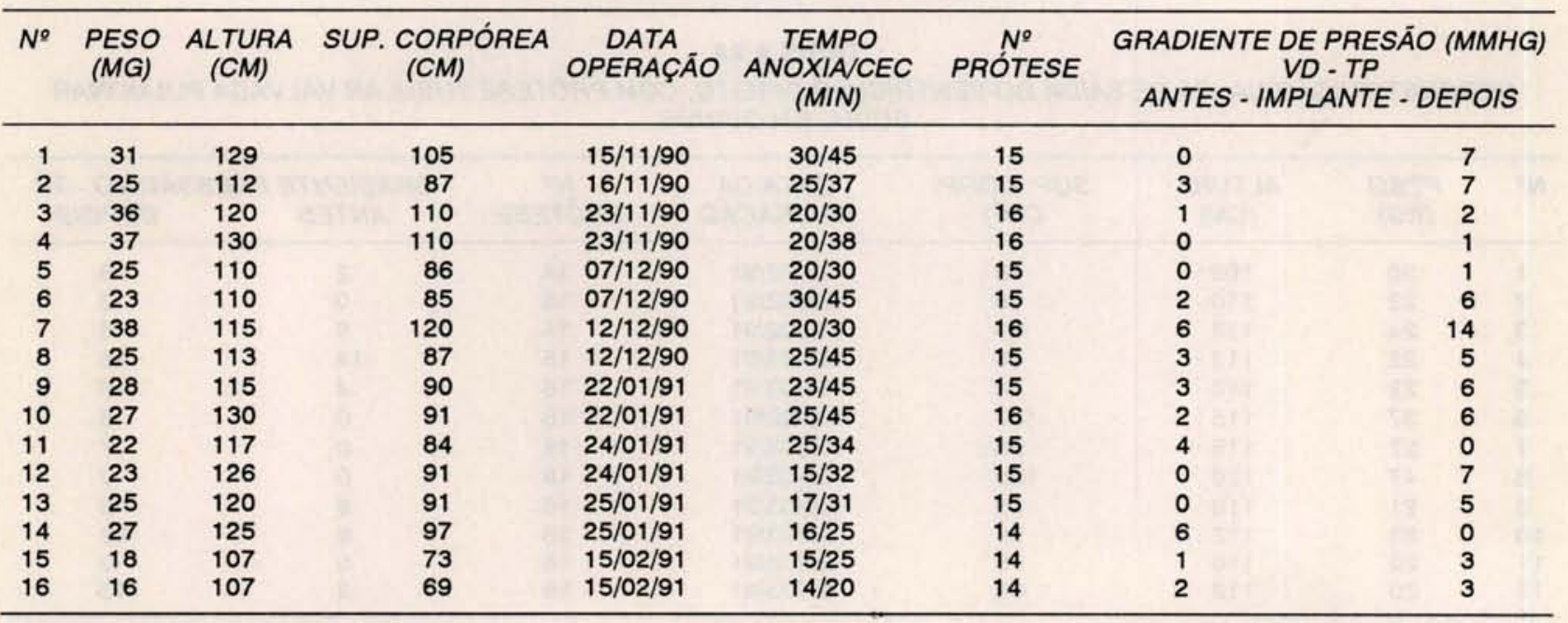

TABELA $1 B$

TESTE DE WILCOXON

(ANTES X DEPOIS)

\begin{tabular}{|c|c|c|c|c|c|c|c|c|}
\hline & PAS-S & PAS-D & PVD-S & PVD-D & PTP-S & PTP-D & IC & $\begin{array}{l}\text { GRADIENTE } \\
\text { VD - TP }\end{array}$ \\
\hline $\begin{array}{l}\text { T calculado } \\
\text { T crítico }\end{array}$ & $\begin{array}{l}3,5^{\star} \\
25,0\end{array}$ & $\begin{array}{l}12,0^{*} \\
30,0\end{array}$ & $\begin{array}{l}5,0^{*} \\
30,0\end{array}$ & $\begin{array}{l}1,0 \\
0,0\end{array}$ & $\begin{array}{r}9,5 \\
30,0\end{array}$ & $\begin{array}{l}19,0 \\
21,0\end{array}$ & $\begin{array}{l}46,0 \\
30,0\end{array}$ & $\begin{array}{l}3,5^{*} \\
0,25\end{array}$ \\
\hline
\end{tabular}

PAS: pressão arterial sistêmica; PVD: pressāo ventrículo direito; PTP: pressão tronco pulmonar; IC: índice cardíaco; S: sistólica; $\mathrm{D}$ : diastólica; * estatisticamente significativo. 
MALUF, M. A.; VERDE, J. L.; LEAL, J. C.; CATANI, R.; GARCIA Jr., H. V.; THEVENARD, R.; CARVALHO, A. C.; ANDRADE, J. L.; ANDRADE, J. C. S.; BRAILE, D. M.; LEĀO, L. E. V.; BUFFOLO, E. - Reconstruçāo da valva pulmonar e via de saída do ventrículo direito, com prótese bivalvular e prótese tubular valvada de tronco pulmonar de porco: estudo experimental e aplicaçāo clínica. Rev. Bras. Cir. Cardiovasc., 8(1):20-38, 1993.

\section{Técnica Operatória}

\section{Animais de experimentação}

Foram empregadas 28 ovelhas desmamadas, em crescimento, com idades de 2 a 3 anos e peso variando entre $16 \mathrm{~kg}$ e $47 \mathrm{~kg}$ (média $26,0 \mathrm{~kg}$ ), divididas ao acaso, em dois grupos.

O primeiro grupo, constituído por 16 ovelhas, foi sumetido a implante de prótese bivalvular, com o auxílio da CEC (Tabela 1a).

O segundo grupo, constituído por 12 ovelhas, foi submetido a implante de prótese tubular valvada, sem o auxílio da CEC (Tabela 2a).

\section{Ato operatório}

Após punçăo da veia jugular externa esquerda, injetou-se a medicação anestésica: Dormonid $(0,5$ $\mathrm{mg} / \mathrm{kg})$, ou Hypnomidate $(0,2 \mathrm{mg} / \mathrm{kg})$ e Atropina $(0,02$ $\mathrm{mg} / \mathrm{kg}$ ).

O animal devidamente monitorizado (pressāo arterial e venosa, eletrocardiograma e diurese) foi submetido a tricotomia e antissepsia. O campo operatório foi delimitado e o acesso ao coraçāo feito através de toracotomia lateral esquerda, pelo quarto espaço intercostal.

A seguir, foi realizada a monitoraçāo hemodinâmica pré-operatória, com registro e impressāo das curvas pressóricas de: aorta, TP, ventrículo direito(VD), átrio direito (AD) e átrio esquerdo ( $A E)$. Utilizando-se um cateter posicionado no TP, foi realizada a mensuraçāo do débito cardíaco por termodiluiçāo (Thermodilution Probe, Mod 94-030-2,5F, Baxter).

\section{Implante da prótese bivalvular pulmonar suína}

Após administração de heparina, na dose de $400 \mathrm{u} / \mathrm{kg}$ peso, a CEC foi instalada (bomba de CEC de IMC Biomédica e oxigenador de bolhas infantil - Macchi 330), com cânula única posicionada em AD (diâmetro $9 \mathrm{~mm}$ ), e procedeu-se à perfusāo arterial com a cânula posicionada na aorta descendente. Foi realizada hemodiluição total com solução de Ringer Lactato. A perfusāo foi normotérmica com fluxo arterial de $2.41 / \mathrm{min} / \mathrm{m}^{2}$.

O procedimento cirúrgico foi realizado com pinçamento aórtico e a proteção miocárdica com cardioplegia sangüínea normotérmica; a drenagem das cavidades esquerdas deu-se através do $A E$.

TABELA 2A

RECONSTITUIÇÄO DA VIA DE SAIDA DO VENTRÍCULO DIREITO, COM PRÓTESE TUBULAR VALVADA PULMONAR SUINA, EM OVINOS

\begin{tabular}{|c|c|c|c|c|c|c|c|}
\hline$N^{\circ}$ & $\begin{array}{l}\text { PESO } \\
(K G)\end{array}$ & $\begin{array}{l}\text { ALTURA } \\
\text { (CM) }\end{array}$ & $\begin{array}{c}\text { SUP. CORP. } \\
\left(M^{2}\right)\end{array}$ & $\begin{array}{c}\text { DATA DA } \\
\text { OPERAÇĀO }\end{array}$ & $\begin{array}{c}N^{Q} \\
\text { PRÓTESE }\end{array}$ & $\begin{array}{c}\text { GRADIENTE } \\
\text { ANTES }\end{array}$ & $\begin{array}{c}\text { PRESSĀO VD - TP } \\
\text { DEPOIS }\end{array}$ \\
\hline 1 & 20 & 109 & 78 & $22 / 02 / 91$ & 14 & 2 & 9 \\
\hline 2 & 22 & 110 & 78 & $22 / 02 / 91$ & 15 & 0 & 2 \\
\hline 3 & 24 & 112 & 80 & $22 / 02 / 91$ & 15 & 0 & 6 \\
\hline 4 & 22 & 113 & 80 & $01 / 03 / 91$ & 15 & 14 & 16 \\
\hline 5 & 22 & 110 & 78 & $01 / 03 / 91$ & 16 & te & 6 \\
\hline 6 & 37 & 115 & 107 & $08 / 03 / 91$ & 16 & 15 & 6 \\
\hline 7 & 27 & 115 & 98 & $08 / 03 / 91$ & 16 & tater & 7 \\
\hline 8 & 47 & 120 & 120 & $08 / 03 / 91$ & 16 & 0 & 0 \\
\hline 9 & 21 & 110 & 78 & $08 / 03 / 91$ & 15 & 6 & 6 \\
\hline 10 & 23 & 112 & 78 & $25 / 03 / 91$ & 18 & $x=$ & 22 \\
\hline 11 & 20 & 110 & 78 & $26 / 03 / 91$ & 18 & 0 & 0 \\
\hline 12 & 20 & 112 & 79 & $27 / 03 / 91$ & 18 & 3 & 13 \\
\hline
\end{tabular}

TABELA 2B

TESTE WILCOXON

(ANTES X DEPOIS)

\begin{tabular}{|c|c|c|c|c|c|c|c|c|}
\hline & PAS-S & PAS-D & PVD-S & PVD-D & PTP-S & PTP-D & IC & $\begin{array}{c}\text { GRADIENTE } \\
\text { VD - TP }\end{array}$ \\
\hline $\begin{array}{l}\text { T calculado } \\
\text { T crítico }\end{array}$ & $\begin{array}{c}0^{*} \\
14,0\end{array}$ & $\begin{array}{c}0^{*} \\
14,0\end{array}$ & $\begin{array}{c}0^{*} \\
14,0\end{array}$ & $\begin{array}{r}11,0 \\
6,0\end{array}$ & $\begin{array}{r}18 \\
6\end{array}$ & $\begin{array}{l}18,0 \\
11,0\end{array}$ & $\begin{array}{l}19,5 \\
14,0\end{array}$ & $\begin{array}{l}13,0^{\star} \\
14,0\end{array}$ \\
\hline
\end{tabular}

PAS: pressāo arterial sistêmica; PVD: pressão ventrículo direito; PTP: pressāo tronco pulmonar; S: sistólica; D: diastólica; * estatísticamente significativo. 
MALUF, M. A.; VERDE, J. L.; LEAL, J. C.; CATANI, R.; GARCIA Jr., H. V.; THEVENARD, R.; CARVALHO, A. C.; ANDRADE, J. L.; ANDRADE, J. C. S.; BRAILE, D. M.; LEĀO, L. E. V.; BUFFOLO, E. - Reconstruçāo da valva pulmonar e via de saída do ventrículo direito, com prótese bivalvular e prótese tubular valvada de tronco pulmonar de porco: estudo experimental e aplicaçāo clínica. Rev. Bras. Cir. Cardiovasc., 8(1):20-38, 1993.

Foi realizada ventriculotomia de aproximadamente 3 a $4 \mathrm{~cm}$ de extensāo. Usando-se o dilatador de Hegar, para medir o diâmetro do anel pulmonar, que deveria ter as mesmas dimensōes do enxerto bivalvular, procedeu-se à sua lavagem com $3000 \mathrm{ml}$ de soluçāo fisiológica, para retirar o excesso de formaldeído.

A incisāo foi, entāo, prolongada em direção ao $T P$, seccionando-se o anel e ressecando a face anterior dessas estruturas, incluindo as válvulas anterior e posterior direita da valva pulmonar (Figura 3a). A seguir, foram passados dois pontos de Polipropileno 5-0 nas comissuras da válvula remanescentes e $3 \mathrm{~mm}$ abaixo do ponto de inserção das válvulas do enxerto bivalvular.

O enxerto foi suturado no TP, anel e VSVD, empregando chuleio simples de Polipropileno 5-0 (Figura 3b).

Após despinçamento da aorta e recuperaçāo dos batimentos cardíacos, o circuito da CEC foi desligado.

Depois da estabilizaçāo hemodinâmica do ani- mal, foi realizada monitoração das pressōes e mensuraçāo do débito cardíaco.

O funcionamento da prótese foi analisado mediante ecodopplercardiograma (marca Esaoete, modelo 5000 , com transdutor de $5 \mathrm{MHz}$ ).

Com o tórax aberto, o transdutor foi posicionado acima da prótese e realizado o estudo mediante cortes longitudinal e transversal.

Ao final do experimento, os animais foram sacrificados devido à presença de sangramento pulmonar, decorrente do uso da CEC.

\section{Implante de prótese tubular valvada pulmonar suína}

Após administração de heparina na dose de $200 \mu / \mathrm{kg}$ peso, foi dissecado o TP, cadarçado e medido o diâmetro externo do anel pulmonar. A seguir, foi escolhida e lavada a prótese tubular valvada do tamanho correspondente.

Um ponto de Polipropileno 4-0 foi passado na
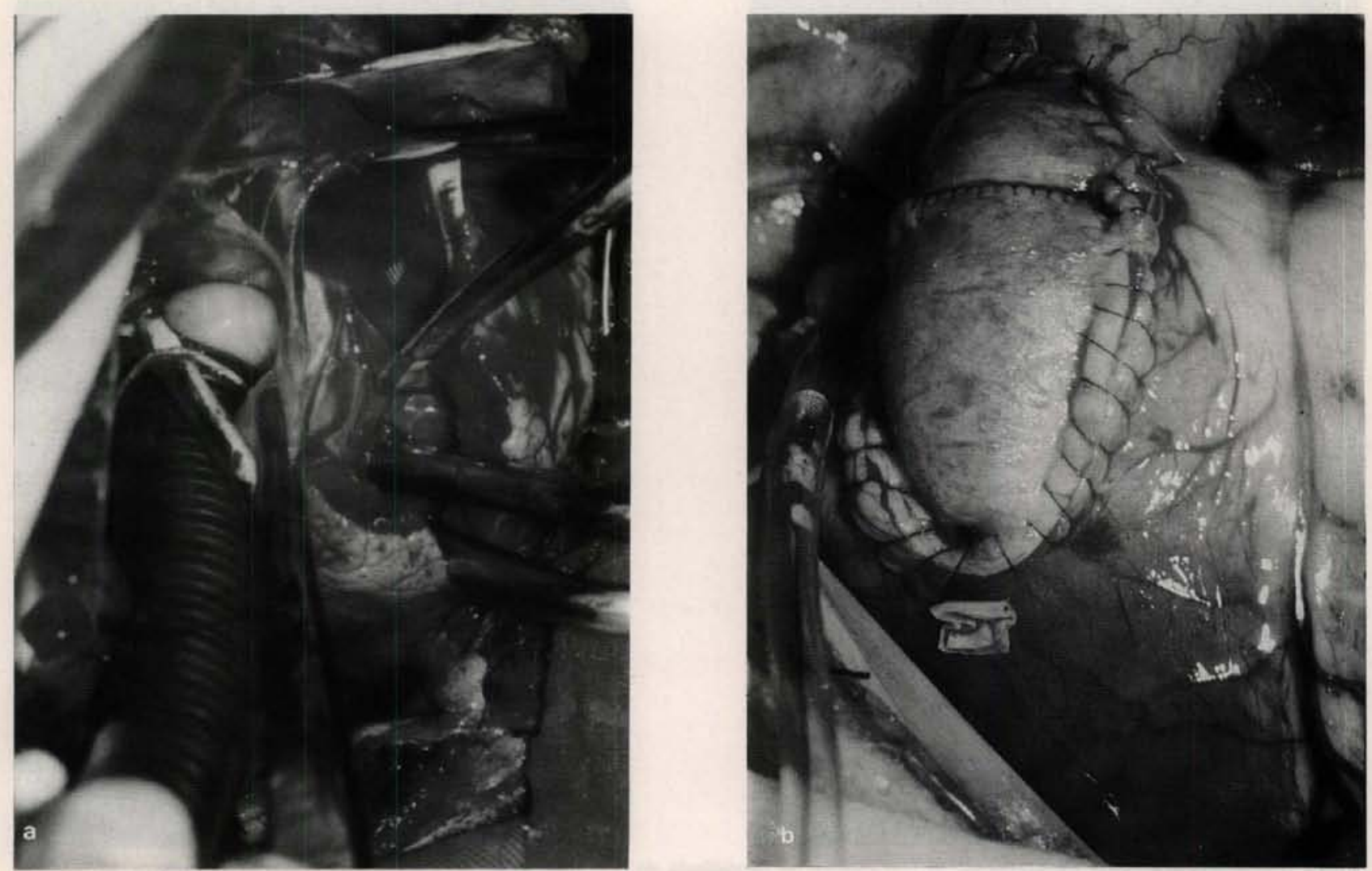

Fig. 3 - Fotografia operatória experimental. a) ressecção das válvulas anterior e posterior direita; b) prótese bivalvular implantada. 
MALUF, M. A.; VERDE, J. L.; LEAL, J. C.; CATANI, R.; GARCIA Jr., H. V.; THEVENARD, R.; CARVALHO, A. C.; ANDRADE, J. L.; ANDRADE, J. C. S.; BRAILE, D. M.; LEẢO, L. E. V.; BUFFOLO, E. - Reconstruçāo da valva pulmonar e via de saída do ventrículo direito, com prótese bivalvular e prótese tubular valvada de tronco pulmonar de porco: estudo experimental e aplicação clínica. Rev. Bras. Cir. Cardiovasc., 8(1):20-38, 1993.

parede ventricular da via de saída do ventrículo direito e, após discreta traçāo, foi realizado pinçamento tangencial amplo da parede do infundíbulo, com pinça tipo De Bakey, analisando-se, a seguir, as condiçōes hemodinâmicas. Quando houve alteraçōes, como: hipotensāo, arritmia cardíaca ou distensāo do ventrículo direito, a pinça foi liberada e novo procedimento foi realizado após alguns minutos. Em condiçōes hemodinâmicas estáveis, a parede ventricular foi incisada com bisturi e ampliada com tesoura tipo Dietrich, até ficar do mesmo diâmetro da boca anastomótica proximal da prótese.

Com fio de Polipropileno 5-0, foi realizada a anastomose proximal do conduto na VSVD, com sutura contínua englobando todas as camadas da parede ventricular (Figura 4a). Terminado esse tempo cirúrgico, a pinça foi deslocada para o próprio tubo, aproveiando-se para analisar o seu enchimento, rever a hemostasia e adequar o comprimento da prótese.

A anastomose distal foi feita utilizando-se pinça tipo Beck, para o pinçamento tangencional do TP. Em condiçōes hemodinâmicas estáveis, a parede
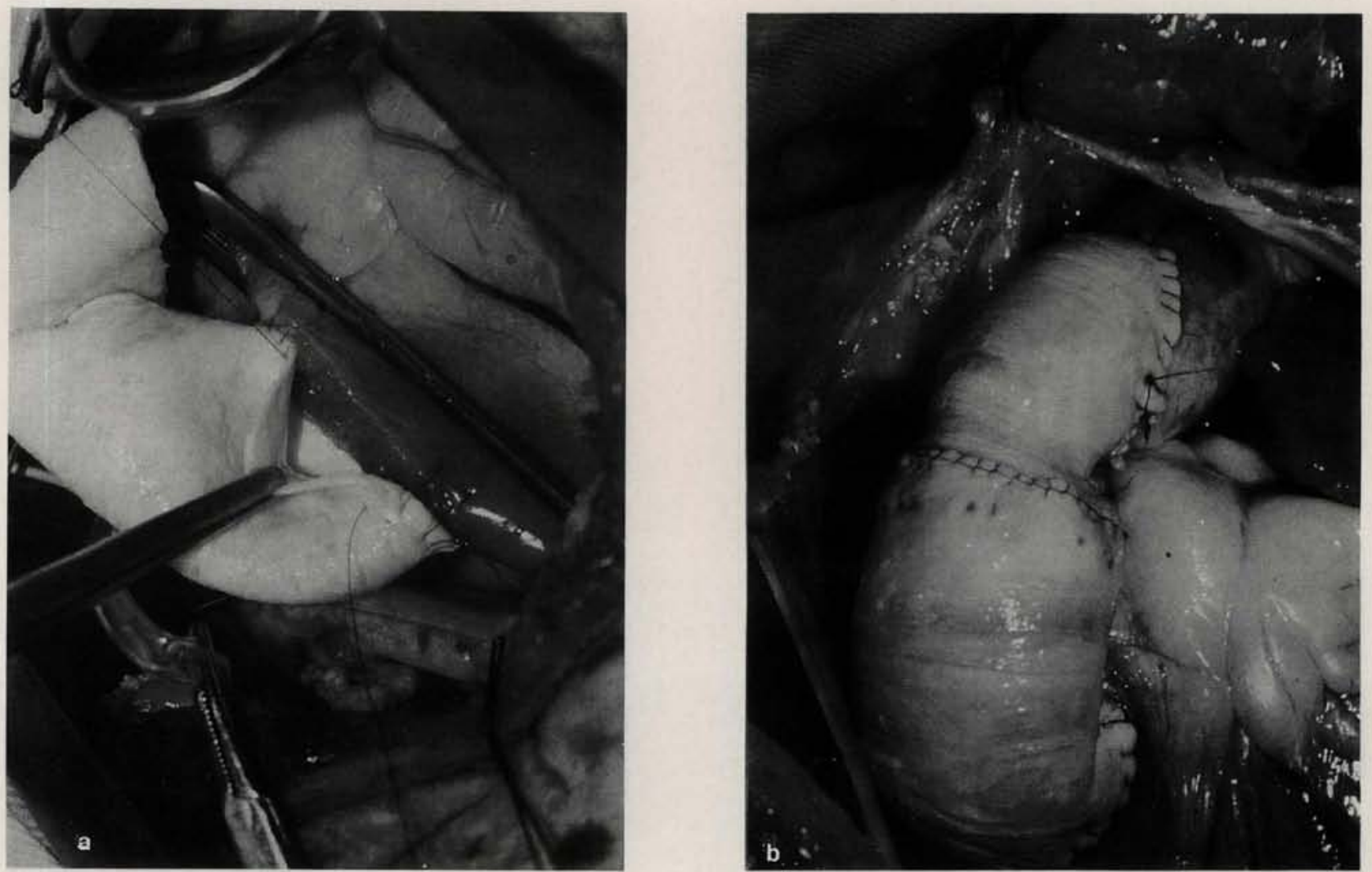

Fig. 4 - Fotografia operatória experimental. a) pinçamento do infundíbulo do ventrículo direito e anastomose proximal da prótese; b) prótese implantada, seguida de ligadura do tronco pulmonar. do TP foi incisada com bisturi e completada a abertura com tesoura Dietrich. Com fio de Polidistal da prótese no TP.

Após liberadas as pinças e feita a revisāo da hemostasia, foi ligado o TP acima do plano valvar, desviando o fluxo do sangue através da prótese tubular (Figura 4b) e, a seguir, foram realizadas as mensuraçōes hemodinâmicas.

Com o intuito de facilitar a realização do ecocardiograma no pós-operatório, foi ressecada a costela próxima ao conduto. O tórax foi drenado e fechado por planos. Após recuperação anestésica, foram retirados o cateter arterial e o dreno, seguindo-se a desentubaçāo.

Todos os animais permaneceram no biotério em observação por 24 horas e, após esse período, foram transportados para local aberto, dispondo de pastagem e raçāo balanceada.

As avaliaçōes ecodopplercardiográficas foram realizadas entre o $3^{\circ}$ e $\circ 4^{\circ}$ mês de pós-operatório, usando-se transdutor de $3,5 \mathrm{MHz}$ e $5 \mathrm{MHz}$, através propileno $5-0$, procedeu-se à sutura do extremo 
MALUF, M. A.; VERDE, J. L.; LEAL, J. C.; CATANI, R.; GARCIA Jr., H. V.; THEVENARD, R.; CARVALHO, A. C.; ANDRADE, J. L.; ANDRADE, J. C. S.; BRAILE, D. M.; LEĀO, L. E. V.; BUFFOLO, E. - Reconstruçāo da valva pulmonar e via de saída do ventrículo direito, com prótese bivalvular e prótese tubular valvada de tronco pulmonar de porco: estudo experimental e aplicação clínica. Rev. Bras. Cir. Cardiovasc., 8(1):20-38, 1993.

de "janela costal" deixada ao mesmo nível da prótese implantada.

As avaliaçōes hemodinâmica e cineangiográfica foram realizadas em torno do $6^{\circ}$ mês de evolução e, a seguir, os animais foram sacrificados, conforme o prazo estipulado para o estudo.

Finalmente, todas as próteses com possibilidades de recuperaçăo foram encaminhadas para estudo histológico e histoquímico. Foram avaliadas quanto à integridade das válvulas e calcificaçōes grosseiras.

\section{APLICAÇĀO CLÍNICA}

A prótese bivalvular pulmonar suína foi implantada em 3 pacientes e a prótese tubulada valvada em 2 pacientes (Tabela 3 ), todos portadores de cardiopatias congênitas complexas, internados no setor de Cardiopatias Congênitas do Hospital Sāo Paulo da Escola Paulista de Medicina.

\section{Prótese Bivalvular}

Caso de $\mathrm{n}^{\circ}$ 1: F. P., feminina, raça branca, 16 anos de idade, apresentava cianose desde os 6 meses de vida, raras crises de hipóxia, conseguindo desenvolvimento pondo-estatural normal e limitação física aos grandes esforços. O aumento da cianose e da dispnéia aos médios esforços obrigou sua internaçāo.

Os estudos ecodoplercardiográfico, hemodinâmico e cineangiográfico confirmaram o diagnós- tico de tétrade de Fallot, apresentando dextroposiçāo da aorta de aproximadamente $50 \%$ e hipoplasia do anel pulmonar.

A correção cirúrgica foi realizada em 27/6/91, com auxílio da CEC e proteçāo do miocárdio com infusāo de soluçāo cardioplégica sangüínea hipotérmica.

Através da incisão longitudinal no infundíbulo do VD, foi abordada e fechada comunicaçāo interventricular (CIV) de $30 \mathrm{~mm}$, empregando placa de pericárdio bovino em sutura contínua.

A presença de um anel pulmonar de $12 \mathrm{~mm}$ obrigou a sua ampliaçāo e do TP com prótese bivalvular pulmonar suína de $18 \mathrm{~mm}$, reconstituindo a valva, após preservar a válvula posterior esquerda.

Caso de $n^{\circ}$ 2: A. S. F., masculino, raça branca, 7 anos de idade, apresentava sopro cardíaco e discreta cianose desde o nascimento.

A falta de desenvolvimento físico e a insuficiência cardíaca congestiva (ICC) foram os motivos de sua internaçāo.

Os estudos ecodopplercardiográfico, hemodinâmico e cineangiográfico mostraram tratar-se de tétrade de Fallot com agenesia da valva pulmonar e hipoplasia do anel, permitindo moderada IPV. As artérias pulmonares apresentavam-se dilatadas.

A correçāo cirúrgica foi realizada em 21/11/91, com auxílio da CEC e a proteçāo do miocárdio, com infusão de solução cardioplégica sangüínea hipotérmica.

A CIV foi abordada pelo $A D$ e fechada com

TABELA 3

PACIENTES SUBMETIDOS A RECONSTITUIÇĀO DA VALVA PULMONAR E VIA DE SAIDA DO VENTRICULO DIREITO COM PRÓTESE BIVALVULAR OU PRÓTESE TUBULAR VALVADA PULMONAR SUÍNA

\begin{tabular}{|c|c|c|c|c|c|c|c|c|c|}
\hline \multirow{2}{*}{ PACIENTE } & \multirow[b]{2}{*}{ SEXO } & \multirow[b]{2}{*}{ IDADE } & \multirow[b]{2}{*}{ DIAGNÓSTICO } & \multirow[b]{2}{*}{$\begin{array}{l}\text { TIPO DE } \\
\text { PRÓTESE }\end{array}$} & \multirow{2}{*}{$\begin{array}{l}\text { AVALIA } \\
\text { No PRÓTESE } \\
\text { (MM) }\end{array}$} & \multicolumn{3}{|c|}{$\begin{array}{c}\text { AÇĀO ECO-DOPPLERCARDIOGF } \\
\text { PÓS-OPERATÓRIA }\end{array}$} & \multirow{2}{*}{$\begin{array}{l}\text { RÁFICA } \\
\text { CLASSE } \\
\text { FUNCIONAL } \\
\text { (NYHA) }\end{array}$} \\
\hline & & & & & & $\begin{array}{l}\text { SHUNT } \\
\text { RESIDUAL }\end{array}$ & $I P V$ & $\begin{array}{c}\text { GRADIENTE } \\
\text { VD-TP } \\
\text { (MMHG) }\end{array}$ & \\
\hline FP & $\mathrm{F}$ & 16 & T. Fallot & Bivalvular & 18 & - & + & 10 & 1 \\
\hline ASF & $M$ & 7 & $\begin{array}{l}\text { T. Fallot+ } \\
\text { Agenesia VP }\end{array}$ & Bivalvular & 12 & - & + & 18 & 1 \\
\hline THH & $\mathrm{F}$ & 2 & T. Fallot & Bivalvular & 11 & - & + & 20 & 1 \\
\hline CSA & $\mathrm{F}$ & 10 & $\begin{array}{l}\text { At. Pulm.+ } \\
\text { CIV }\end{array}$ & Tub. valvado & 18 & - & - & 15 & 1 \\
\hline AKO & $M$ & 5 & $\begin{array}{l}\mathrm{TCG}+\mathrm{ClV}+ \\
\mathrm{EP}\end{array}$ & Tub. valvado & 16 & - & - & 18 & 1 \\
\hline
\end{tabular}

CIV; comunicação interventricular; TCG: transposiçāo corrigida das grandes artérias; IPV: insuficiência pulmonar valvar; VD: ventrículo direito; TP: tronco pulmonar. 
MALUF, M. A.; VERDE, J. L.; LEAL, J. C.; CATANI, R.; GARCIA Jr., H. V.; THEVENARD, R.; CARVALHO, A. C.; ANDRADE, J. L.; ANDRADE, J. C. S.; BRAILE, D. M.; LEẢO, L. E. V.; BUFFOLO, E. - Reconstruçāo da valva pulmonar e via de saída do ventrículo direito, com prótese bivalvular e prótese tubular valvada de tronco pulmonar de porco: estudo experimental e aplicação clínica. Rev. Bras. Cir. Cardiovasc., 8(1):20-38, 1993.

placa de pericárdio bovino em sutura contínua. Uma incisão longitudinal foi praticada no infundíbulo do $V D$, em direção ao TP, seccionando o anel pulmonar estreito que apresentava apenas uma válvula rudimentar aderida à parede que, após cuidadosa dissecçāo, adquiriu discreta mobilidade. A valva pulmonar foi reconstituída com prótese bivalvular pulmonar suína de $12 \mathrm{~mm}$.

Caso de $n^{2}$ 3: T. H. H., feminina, raça amarela, 2 anos de idade, apresentava cianose desde os 3 meses de vida. A piora da cianose e a poliglobulia determinaram as avaliaçōes hemodinâmica e cineangiográfica, confirmando-se o diagnóstico de tétrade de Fallot, associada à hipoplasia do anel e TP.

Em 24/2/92 foi submetida a correçāo cirúrgica com auxílio da CEC e proteção do miocárdio com infusāo contínua de solução cardioplégica sangüínea hipotérmica, através do seio coronário (retroplegia).

A CIV foi abordada através de atriotomia direita e fechada com placa de pericárdio bovino em sutura contínua. Uma incisão longitudinal foi praticada na VSVD, anel e TP, preservando a válvula posterior esquerda. A reconstituição da valva foi realizada com prótese bivalvular pulmonar suína de $11 \mathrm{~mm}$.

\section{Prótese Tubular Valvada}

Caso de $n^{\circ} 4$ : C. S. A., feminina, raça negra, de 10 anos de idade, apresentava cianose desde o nascimento; evoluiu bem até os 9 anos de idade, quando, por motivo de sua limitação física, foi submetida a operação de Blalock-Taussig modificado, com ligadura de artérias brônquicas.

Os estudos ecodopplercardiográfico, hemodinâmico e cineangiográfico confirmaram o diagnóstico de tétrade de Fallot com atresia pulmonar e Blalock-Taussig pérvio.

A correção cirúrgica foi realizada em 25/05/91 com auxílio da CEC e proteção miocárdica com infusão de solução cardioplégica hipotérmica. Após ligadura do shunt e através de ventriculotomia longitudinal no infundíbulo do VD, foi fechada a CIV com placa de pericárdio bovino em sutura contínua e foi implantada uma prótese tubular valvada de 18 $\mathrm{mm}$ entre $\circ \mathrm{VD}$ e artérias pulmonares.

Caso de $n^{2}$ 5: A. K. O., masculino, raça amarela, 5 anos de idade, apresentava cianose desde o nascimento, permanecendo pouco sintomático.

Os estudos ecodopplercardiográfico, hemodinâmico e cineangiográfico mostraram transposição corrigida das grandes artérias (TCGA) associada a CIV e estenose subpulmonar.
A correção cirúrgica foi realizada em 19/12/91, com auxílio da CEC e proteção miocárdica com infusão de solução cardioplégica sangüínea hipotérmica.

A CIV foi abordada através de aortotomia e fechada com placa de pericárdio bovino em sutura contínua.

Para a reconstituição do fluxo pulmonar, foi interposta uma prótese tubular valvada de $16 \mathrm{~mm}$ entre o ventrículo esquerdo (ventrículo venoso) e artéria pulmonar direita.

\section{RESULTADOS}

Prótese Bivalvular Pulmonar Suína

\section{Avaliaçāo hemodinâmica intra-operatória}

Dezesseis ovinos foram submetidos a implante do enxerto bivalvular. $O$ tempo de CEC variou entre 20 min e 45 min (média $34,2 \pm 8,4$ ) e o tempo de pinçamento aórtico, entre $14 \mathrm{~min}$ e $30 \mathrm{~min}$ (média $21,3 \pm 5,1$ ).

Os enxertos implantados apresentavam o mesmo diâmetro do anel pulmonar do animal, medido pelo dilatador de Hegar, com o coração em assistolia.

Foi usado enxerto de $15 \mathrm{~mm}$ em $9(56,3 \%)$ casos, $16 \mathrm{~mm}$ em $4(25 \%)$ e $14 \mathrm{~mm}$ em $3(18,7 \%)$ casos (Tabela 1a).

Os dados da monitoração hemodinâmica, antes e imediatamente após o implante da prótese, mostraram:

- Queda da pressão arterial sistêmica (PAS), sistólica (S) e diastólica (D);

- Aumento da pressão do VD (PVD) $S$ e D; e aumento da pressão do TP (PTP), S. O teste de Wilcoxon demonstrou que esses valores foram estatisticamente significantes.

Por outro lado, houve:

- Aumento da PVD-D;

- Queda do índice cardíaco (IC); valores estes que não foram estatisticamente significantes.

Nos dados da avaliaçāo dos gradientes VD-TP antes e após o implante, foram verificados aumentos significantes, sob o ponto de vista estatístico. Observou-se, contudo, que o gradiente médio após implante foi de $4,6 \pm 3,6 \mathrm{mmHg}$ e apenas 1 caso (ovelha de $n^{2} 7$ ) teve gradiente acima de $10 \mathrm{mmHg}$ (Tabela 1b). 


\section{Avaliaçāo ecodopplercadiográfica intra- operatória}

O exame foi realizado imediatamente após a saída de CEC, ainda com o tórax aberto, usandose transdutor de $5 \mathrm{MHz}$.

Em $10(63,5 \%)$ casos, houve condiçōes adequadas de analisar o traçado ecocardiográfico.

Com o corte transversal da base do coração, foi possível observar a mobilidade da valva pulmonar, fechando no mesmo plano, e avaliar a VSVD.

Ao Doppler foram detectados gradientes transvalvares que variaram entre $1,2 \mathrm{mmHg}$ e $12,1 \mathrm{mmHg}$ (média $4,9+3,2$ )

A insuficiência pulmonar valvar foi considerada discreta em 5 casos $(1,2,5,7,8)$. Não foi detectada regurgitação pulmonar nos 5 casos $(3,4,6,9,10)$ restantes.

\section{Prótese Tubular Valvada Pulmonar Suína}

\section{Avaliação hemodinâmica intra-operatória}

Doze ovinos foram submetidos a implante da prótese tubular valvada. $O$ diâmetro da prótese foi determinado pela medida externa do anel pulmonar, sendo usado um diâmetro imediatamente inferior (após descontar a espessura da parede do TP do animal).

Foram empregadas próteses de $15 \mathrm{~mm}$ em 4 $(33,3 \%)$ casos; de $16 \mathrm{~mm}$ em $4(33,3 \%)$ casos; de $18 \mathrm{~mm}$ em $3(25 \%)$ casos e de $14 \mathrm{~mm}$ em $1(8,3 \%)$ caso (Tabela 2a).

Os dados da monitoração hemodinâmica, obtidos antes e depois do implante da prótese tubular:

- Queda da PAS-S e D;

- Aumento da PVD-S. Conforme aplicação do teste de Wilcoxon, esses valores foram estatisticamente significantes;

- Aumento da PVD-D;

- Aumentos do PTP-S e D foram estatisticamente significantes.

$\mathrm{Na}$ avaliaçāo das pressōes registradas, houve aumento dos gradientes VD e TP após implante, sendo estes dados estatisticamente significantes, embora a média de gradientes após o implante tenha sido de apenas $7,4 \pm 6,1 \mathrm{mmHg}$, e somente 3 casos $(4,10,12)$ tiveram gradientes acima de 10 $\mathrm{mmHg}$ (Tabela 2b).

\section{Avaliação ecopplercardiográfica pós-operatória tardia}

Devido às dificuldades técnicas para avaliar a prótese tubular durante 0 ato operatório, o exame ecodopplercardiográfico foi realizado no $3^{2}$ ou $4^{2}$ mês de evolução com transdutor de $5 \mathrm{MHz}$.

Os 7 ovinos $(2,3,4,5,6,10,12)$ sobreviventes foram estudados com evolução de 99 a 135 dias de pós-operatório (média 119).

O corte paraesternal transversal, da base do coração, mostrou a valva do conduto sem espessamentos, com boa mobilidade durante a abertura, sem apresentar insuficiência valvar durante seu fechamento. Nestes animais a avaliação ecodopplercardiográfica mostrou gradientes que variaram entre $9,85 \mathrm{mmHg}$ a $49 \mathrm{mmHg}$ (média 19,7).

$\mathrm{Na}$ ovelha de $n^{2} 4$, foj detectado gradiente de $49 \mathrm{mmHg}$ devido à estenose na anastomose distal, magnificado, talvez, pela prenhez em curso.

A ovelha de $n^{2} 10$, após conseguir levar a termo sua prenhez, parindo um filhote sadio, apresentou gradiente pressórico de $8,3 \mathrm{mmHg}$ através da prótese.

\section{Avaliação hemodinâmica e cineangiográfica pós-operatória tardia}

Quatro ovinos $(2,6,10,12)$ foram submetidos a estudo hemodinâmico e cineangiográfico entre 170 e 205 dias de pós-operatório (média 184,2).

Através da ventriculografia direita, foi observada livre passagem de contraste através da prótese, para as artérias pulmonares, em todos os casos. A VSVD apresentava-se obliterada, devido à ligadura do TP.

Em 3 ovinos $(2,6,12)$ houve aumento do gradiente pressórico, entre $19 \mathrm{mmHg}$ e $27 \mathrm{mmHg}$ (média $22,3)$, quando comparado com os resultados obtidos durante a operação.

A ovelha de $n^{\circ} 10$ apresentou queda do gradiente pressórico em relação aos dados da operação.

Houve calcificação intensa da parede da prótese, porém a valva pulmonar apresentou-se com boa mobilidade e suficiente.

\section{Mortalidade}

Ocorreram oito óbitos entre o $90^{\circ}$ e $175^{\circ}$ dia de pós-operatório (média 132,7).

Em 3 ovinos $(1,3,4)$, o óbito foi relacionado com a operação (endocardite infecciosa, hipertensão pulmonar e falência ventricular direita). Em 5 ovinos $(5,7,8,9,11)$, o estudo necroscópico não atribuiu a causa mortis ao sistema cardiovascular. 
MALUF, M. A.; VERDE, J. L.; LEAL, J. C.; CATANI, R.; GARCIA Jr., H. V.; THEVENARD, R.; CARVALHO, A. C.; ANDRADE, J. L.; ANDRADE, J. C. S.; BRAILE, D. M.; LEĀO, L. E. V.; BUFFOLO, E. - Reconstruçāo da valva pulmonar e via de saída do ventrículo direito, com prótese bivalvular e prótese tubular valvada de tronco pulmonar de porco: estudo experimental e aplicaçảo clínica. Rev. Bras. Cir. Cardiovasc., 8(1):20-38, 1993.

\section{Sacrifício dos Animais}

Quatro ovinos $(2,6,10,12)$ com evolução de 170 a 205 dias (média 184) de pós-operatório, foram sacrificados após realizar-se estudo hemodinâmico e cineangiográfico, conforme o prazo de evolução estipulado.

\section{Estudo Histológico e Histoquímico das Próteses Recuperadas}

Foram estudadas 7 próteses $(2,3,4,6,7,10$, 12), recuperadas no período de 90 a 205 dias (média 161) de implante.

Observou-se espessamento discreto da íntima em todos os casos; a calcificação esteve presente na regiāo subintimal e/ou na camada média, sem comprometer a valva pulmonar. Apenas 1 caso apresentou calcificaçāo focal das válvulas. 0 exsudato inflamatório foi comum a todos os casos e estava constituído por células mononucleares. Dois casos apresentaram trombose parietal discreta em organização.

\section{Evolução dos Pacientes Operados}

\section{Avaliação clínica}

Todos os pacientes evoluíram bem e se encontraram em classe funcional I (NYHA), num período de 3 a 12 meses de pós-operatório. $O$ caso de $n^{2}$ 3 encontra-se bem, apesar das intercorrências sofridas no pós-operatório imediato: insuficiência renal aguda, necessitando diálise peritoneal e entubação prolongada.

\section{Avaliação ecodopplercardiográfica}

Casos de $n^{\circ}$ 1, 2, 3: Não houve CIV residual demonstrável ao exame com Doppler em nenhum caso.

A valva pulmonar apresentava boa mobilidade, com coaptação de suas válvulas no mesmo plano, e sem restrição na sua abertura. A IPV detectada com Doppler foi considerada discreta em todos os casos.

A presença de gradientes de pressão entre o VD e TP, quantificados entre $10 \mathrm{mmHg}$ e $20 \mathrm{mmHg}$, não foi inferida à prótese e, sim, à persistência de hipertrofia muscular do infundíbulo e do próprio VD. A contratilidade de ambos os ventrículos não apresentou mudança, quando comparada com o exame pré-operatório.
Casos de $n^{2}$ 4, 5: Não foi detectada CIV residual demonstrável ao exame com Doppler.

A valva da prótese apresentava boa mobilidade, sem espessamentos e sem insuficiência.

0 registro do gradiente de pressāo entre a câmara ventricular $\mathrm{e}$ as artérias pulmonares variou entre $15 \mathrm{mmHg}$ e $18 \mathrm{mmHg}$ e a função ventrícular estava preservada (Tabela 3 ).

\section{COMENTÁRIOS}

A experiência recente, baseada, fundamentalmente, em seguimento pós-operatório tardio de pacientes submetidos a correção da tétrade de Fallot, mostra claramente a repercussão da IPV. As alteraçōes hemodinâmicas se caracterizam pelo aumento do volume diastólico final e queda da fração de ejeção do VD, levando a longo prazo a dilatação e falência ventricular direita, além de graves arritmias, modificando, assim, o prognóstico dos pacientes submetidos às operaçōes corretivas ${ }^{13,17}$.

Grande esforço tem sido dirigido, portanto, na possibilidade de utilizar, nos casos onde é imprescindível a ampliaçāo do anel valvar pulmonar, uma prótese que permita a manutenção da insuficiência pulmonar valvar.

Pouco satisfeitos com os resultados obtidos com o uso de enxertos monovalvulados, decidiu-se, através de concepção original, confeccionar uma prótese bivalvular "em telha", utilizando tecido arterial pulmonar suíno conservado. Desconhecia-se, na épo$\mathrm{ca}$, os trabalhos de MARCHAND ${ }^{34}$ e EGUCHI \& ASANO ${ }^{14}$.

A decisão de usar o tronco pulmonar junto à sua valva para a construção da prótese foi baseada em algumas características próprias do tecido pulmonar: parede fina, variedade de diâmetros e calcificação restrita à parede do tubo quando de seu implante em território venoso ${ }^{32}$.

A extensa experiência do Instituto de Moléstias Cardiovasculares (São José do Rio Preto, SP) e da Escola Paulista de Medicina ${ }^{7}$, com preparo e preservação de tecidos em solução de glutaraldeído, permitiu adequada fixação do tecido pulmonar, confirmada pelos testes de qualidade.

A idéia da montagem com dois segmentos de pulmonar foi concebida considerando-se a vantagem de usar o mesmo tecido para ampliar o tronco pulmonar e a via de saída do ventrículo direito. Por ter conhecimento da alta incidência de estenose proximal quando foi usado tecido de Dacron ou pericárdio 21,27 , ou dilatação aneurismática do enxerto 20,54 , acreditamos que esta sugestão seja 
contribuição original, năo tendo sido encontrado trabalho semelhante na literatura consultada.

O emprego de uma prótese bivalvular "em teIha" teve como vantagens: 1) maior facilidade na reconstituição da valva pulmonar, preservando-se apenas uma válvula do próprio paciente; 2 ) melhor abertura, sem restriçōes, devido à presença de três comissuras; 3 ) fechamento das válvulas no mesmo plano valvar; 4) possibilidade de crescimento do anel pulmonar, às custas de sua porção posterior; 5) conter duas válvulas nativas (pulmonar suína), finas e resistentes, com forma anatômica apropriada, inseridas naturalmente no seu anel (sem interposição de suturas); 6) configuração côncavo-convexa de suas paredes, que permitem adaptação quase natural na via de saída do ventrículo direito, superior a outras próteses construídas artesanalmente.

Pela sua condição de tecido heterólogo, o enxerto estaria sujeito àscomplicaçōes já descritas em próteses biológicas, como calcificação (geralmente respeitando as válvulas), endocardite infecciosa, tromboembolismo e rotura das válvulas.

Neste modelo experimental, da mesma forma que AUSTEN et alii ${ }^{1}$ e EGUCHI \& ASANO ${ }^{14}$, foi realizada uma ampla ressecção da via de saída do ventrículo direito, incluindo duas válvulas da valva pulmonar, no intuito de estabelecer uma situaçāo semelhante à estenose infundibular da tétrade de Fallot.

O implante do enxerto bivalvular, nestas condiçōes, mostrou que é possível reconstituir a valva pulmonar com três válvulas e a via de saída do ventrículo direito, deixando adequada suficiência valvar e gradientes pouco significativos. Esta sugestão é contrária àquela de OKU et alii ${ }^{37}$, que acreditaram que o emprego de telha monovalvular, transformando a valva pulmonar em bivalvular, deixaria menor gradiente sistólico e IPV menos expressiva.

O emprego de animais de experimentação foi um passo decisivo para observar o funcionamento da prótese in vivo.

Ao contrário de outros trabalhos $1,4,16,48$ que utilizaram cães, a escolha de ovinos (BAILEY et alii 2) para este experimento teve diversas vantagens. Trata-se de animal dócil, de fácil aquisiçāo e que pode ser mantido em campo aberto durante o tempo necessário.

Do ponto de vista técnico-operatório, não houve dificuldades para a instalaçāo da CEC, tendo-se apenas cuidados com a canulação da aorta, por ter parede frágil que pode dilacerar e sangrar com facilidade. A cânula arterial foi colocada na aorta descendente, com a finalidade de propiciar melhor apresentação. A via de saída do ventrículo direito, nesses animais, é bem desenvolvida, permitindo uma operação confortável e precisa.

O registro de gradientes pressóricos entre o VD e o TP foi bastante confiável. Tal afirmaçāo pode ser suportada pela semelhança dos resultados entre a avaliação hemodinâmica e o estudo ecodopplercardiográfico. Embora fossem estatisticamente significantes quando da comparaçāo dos dados pré e pós-implante, o gradiente médio foi de apenas $4,5 \mathrm{mmHg}$ e somente em 1 caso, maior do que 10 $\mathrm{mmHg}$, demonstrando que a prótese bivalvular não foi obstrutiva, ao contrário da opiniāo de EGUCHI et alii ${ }^{15}$.

O índice cardíaco no pré e no pós-operatório não sofreu alteraçōes estatisticamente significantes, mantendo valor médio de $3,511 / \mathrm{min} / \mathrm{m}^{2}$ e $3,231 /$ $\mathrm{min} / \mathrm{m}^{2}$, respectivamente, possivelmente devido ao curto período de circulação extracorpórea, cuidadosa proteção miocárdica e, claro, adequada função da prótese.

O ecodopplercardiograma intra-operatório foi um método de avaliaçāo importante na correção e meIhoria da técnica operatória. A ausência ou grau discreto de regurgitação pulmonar valvar detectado com este exame demonstrou que a reconstituição da valva pulmonar é possível, com bons resultados. $\mathrm{Na}$ revisão da literatura, nāo encontramos nenhum trabalho esperimental onde o ecocardiograma tenha sido utilizado com esta finalidade, constituíndo-se, portanto, em mais uma contribuição do presente trabalho.

O sacrifício dos animais ao final da experiência foi obrigatório, frente às graves alteraçōes pulmonares após a CEC em ovinos, decorrentes de perda da capacidade de trocas gasosas e intensa hemorragia através das vias aéreas. Não foi possível reverter este quadro, apesar de se usar períodos curtos de perfusāo e das mudanças na composiçāo do perfusato. Tais complicaçōes aparentemente nāo ocorreram na mesma intensidade, nos trabalhos de BAILEY et alii ${ }^{2}$, que também submeteram ovinos à CEC e puderam apresentar evoluçāo tardia de 6 a 52 semanas.

Possivelmente, a realização de novas experiências usando o modelo experimental utilizado nesta pesquisa permitirá conhecer melhor o efeito da CEC sobre o pulmão de ovinos.

A avaliação ecodopplercardiográfica realizada no pós-operatório imediato, em condiçōes hemodinâmicas estáveis, permitiu uma adequada visibilização e avaliação do grau de abertura e do nível de fechamento da valva pulmonar. 
MALUF, M. A.; VERDE, J. L.; LEAL, J. C.; CATANI, R.; GARCIA Jr., H. V.; THEVENARD, R.; CARVALHO, A. C.; ANDRADE, J. L.; ANDRADE, J. C. S.; BRAILE, D. M.; LEÂO, L. E. V.; BUFFOLO, E. - Reconstruçāo da valva puinonar e via de saída do ventrículo direito, com prótese bivalvular e prótese tubular valvada de tronco pulmonar de porco: estudo experimental e aplicação clínica. Rev. Bras. Cir. Cardiovasc., 8(1):20-38, 1993.

O resultado da mensuraçāo dos gradientes entre - VD e TP com o uso de Doppler nos 10 primeiros casos foi considerado confiável e comparável aos dados obtidos na avaliaçāo hemodinâmica, de 4,9 $\mathrm{mmHg}$ e $4,5 \mathrm{mmHg}$, respectivamente.

No que se refere ao crescimento do anel pulmonar, os esrtudos de ROWLATT et alii ${ }^{44}$, demonstram que o crescimento do anel é proporcional ao aumento de peso do indivíduo. Após a confecçāo de tabela de equivalência entre as duas variáveis, foi possível usá-la como referência, tornando reprodutível a ampliaçāo da VSVD ${ }^{39}$

Por esses motivos, quando a ampliaçāo do anel pulmonar for estritamente necessária, o uso de próteses abertas, em forma de telha, teria, como importante vantagem, permitir o crescimento do anel, às custas de sua parede posterior. Por outro lado, o pesquisador estaria obrigado a pensar que, em se tratando de prótese valvar que foi ajustada para o correto fechamento na época da operação, o crescimento do paciente poderia tornar a prótese menos suficiente. Por outro lado, nas circunstâncias citadas, poder-se-ia esperar, também, o crescimento da válvula nativa; esta condiçāo nāo foi demonstrada e pode ser questionável, visto tratar-se de válvula geralmente espessa e de pouca mobilidade. 0 acompanhamento a longo prazo de pacientes em fase de crescimento, submetidos a implante de prótese bivalvular poderá esclarecer estas dúvidas. A principal limitaçăo do presente estudo foi a impossibilidade de realizar essas observaçōes no pósoperatório tardio. A reconstituiçāo da valva pulmonar e ampliação da VSVD, em 3 pacientes portadores de tétrade de Fallot, mostrou condiçōes técnicas apropriadas para seu implante.

O ajuste das válvulas da prótese com a fibrose remanescente foi realizado com bastante precisāo, ficando discreto refluxo pulmonar, detectado ao Doppler no paciente com agenesia da valva pulmonar (caso de $n^{2}$ 2). Com este critério, a prótese bivalvular poderia ser empregada na reconstituiçāo da valva pulmonar e VSVD, quando é realizada a anteriorização das artérias pulmonares pela manobra de LECOMPTE et alii ${ }^{30}$ ou na correçảo do truncus arterious pela técnica de BARBERO-MAR$\mathrm{CIAL}$ et alii $^{3}$, com os mesmos resultados.

- Com o aumento da demanda e desenvolvimento de operaçōes mais complexas, os condutos sintéticos valvulados foram os mais usados, aparecendo porém, complicaçōes relacionadas à válvula (calcificaçăo), ou ao próprio conduto (obstrução por pannus) 9,21.

O desenvolvimento de tecido neointimal espesso (pannus), no interior das próteses sintéticas de baixa porosidade (Woven-Dacron), com formaçāo de trombos e obstruçāo, estimulou a pesquisa com os tubos năo valvulados de PTFE (SPICER et alii 49), prótese de Dacron "trançado" (knitted-Dacron) HARVERICH et alii ${ }^{19}$, ou construindo válvula de pericárdio no interior da prótese de knitted-Dacron (OLIVEIRA et alii ${ }^{38}$ ). Embora os resultados iniciais fossem favoráveis, nāo houve relatos de acompanhamento tardio, nessas publicaçōes.

Por outro lado, a evoluçāo tardia do homoenxerto aórtico, implantado a fresco, mostrou ausência de pannus e maior resistência à calcificação de sua valva (ROSS \& SOMERVILLE ${ }^{43}$ ). Foram estes motivos que levaram KAY \& ROSS 27 a continuar usando os homoenxertos, agora preparando e implantando o homoenxerto pulmonar valvado na VSVD.

O melhor desempenho, a longo prazo, observado nos homoenxertos pulmonares, com índice baixo de calcificação, levou McGRATH et alii ${ }^{33}$ a realizarem um trabalho clínico comparando os homoenxertos aórtico e pulmonar. Segundo a opiniăo dos autores, os bons resultados iniciais, com o homoenxerto pulmonar, deveriam ser avaliados com cautela, pelo curto período de evoluçāo.

Houve várias contribuiçōes nacionais no uso clínico de condutos valvulados montados com tubo de knitted-Dacron e válvula de pericárdio bovino (OLIVEIRA et alii ${ }^{38}$ ), tubo valvulado de pericárdio (MORAES \& RODRIGUES ${ }^{36}$ ), baseado no trabalho de IONESCU \& DEAC ${ }^{26}$, ou trabalhos experimentais com tubo e prótese de pericárdio bovino (SANTOS et alii ${ }^{4}$ ).

Outra complicação que mereceu atenção na evoluçāo das próteses tubulares implantadas esteve relacionada à obstruçāo da anastomose proximal pela compressão extrínseca sob o tecido emendado no tubo (Dacron, pericárdio) ${ }^{28}$.

Engenhosamente, HOOTS \& WATSON Jr. 22 modificaram a prótese, anastomosando um segmento de homoenxerto aórtico no extremo proximal, durante $o$ ato operatório.

Os resultados obtidos com o uso de próteses valvuladas ou nāo valvuladas, sintéticas ou biológicas, homólogas, heterólogas ou autógenas fizeram com que as operaçōes fossem, muitas vezes, consideradas paliativas, pois havia, freqüentemente, necessidade de sua substituiçāo.

Conhecendo-se algumas das vantagens do uso de heteroenxerto pulmonar, em relaçāo ao aórtico, foi idealizada e confeccionada uma prótese tubular valvada a partir do tronco e valva pulmonar suína, para o desenvolvimento desta pesquisa; considerando-se, também, que não há, na literatura, referência a modelo semelhante. 
MALUF, M. A.; VERDE, J. L.; LEAL, J. C.; CATANI, R.; GARCIA Jr., H. V.; THEVENARD, R.; CARVALHO, A. C.; ANDRADE, J. L.; ANDRADE, J. C. S.; BRAILE, D. M.; LEĀO, L. E. V.; BUFFOLO, E. - Reconstruçāo da valva pulmonar e via de saída do ventrículo direito, com prótese bivalvular e prótese tubular valvada de tronco pulmonar de porco: estudo experimental e aplicaçāo clínica. Rev. Bras. Cir. Cardiovasc., 8(1):20-38, 1993.

\section{Características do Conduto:}

- Segmento longo de tronco pulmonar formado por parede fina que auxiliaria a anastomose distal:

- Valva pulmonar nativa, inserida no seu próprio anel;

- Porção proximal constituída por outro segmento de TP, facilitando a anastomose proximal;

- Forma anatômica que favorecia à acomodação na cavidade pericárdica, mantendo-o livre de compressōes extrínsecas;

- Posicionamento da valva pulmonar no mesmo plano da valva aórtica, evitando a insuficiência pulmonar por deformaçōes.

O implante de condutos protéticos entre o VD e artérias pulmonares, com ligadura do TP em animais, foi um modelo experimental muito usado no passado (HURWITT ${ }^{24}$; DONOVAN ${ }^{11}$; GILBERT et alii ${ }^{18}$ ).

A técnica de pinçamento do infundíbulo do VD, para realizar a anastomose proximal, com o modelo de SANTOS et alii ${ }^{46}$, foi conseguida em condiçōes hemodinâmicos estáveis.

$O$ procedimento realizado em ovinos, sem uso da CEC, foi simples, não havendo intercorrências e com a vantagem de que todos sobreviveram à operação. Esta região do VD nesses animais é bem desenvolvida, permitindo o pinçamento sem obstrução ao fluxo sangüíneo para os pulmōes, o que também foi considerado, na escolha deste método para a pesquisa.

Outra técnica de implante do conduto protético, dispensando a CEC e o pinçamento do infundíbulo, foi descrita por BROW et alii ${ }^{8}$. A realização de um pregueamento da parede livre do infundíbulo, passando pontos em " $U$ " apoiados em barras de Teflon, permitiu manter a hemostasia durante a anastomose proximal do tubo. Esta técnica nos pareceu ser mais laboriosa e com oportunidade de apresentar maior sangramento.

Da mesma maneira, não houve dificuldades para realização da anastomose distal no TP, devido ao excelente calibre desta estrutura em ovelhas.

O comprimento da prótese tubular valvada pulmonar permitiu seu implante e acomodação na cavidade pericárdica sem risco de deformaçōes, ou compressōes extrínsecas no fechamento do tórax, como foi descrito por Mc GRATH et alii ${ }^{33}$.

Os gradientes pressóricos entre VD e TP, medidos após implante da prótese, foram estatisticamente significantes quando comparados aos valores obtidos antes do implante; no entanto, o gradiente médio foi de apenas $7,42 \mathrm{mmHg}$. Devido ao desempenho hemodinâmico satisfatório após 0 im- plante da prótese tubular, dispensou-se, neste grupo, a medida do índice cardíaco.

A avaliação pós-operatória periódica e sistemática destas próteses tubulares, mediante procedimentos não invasivos, tais como, exame radiológico de tórax ou exame ecodopplercardiográfico é estritamente necessária para detectar calcificaçāo ou observar o comportamento hemodinâmico das mesmas, dada a pobreza de sintomas que esses pacientes costumam apresentar (ROSS \& SOMERVILLE ${ }^{43}$, SCHLICHTER \& KREUTZER ${ }^{47}$, Mc GRATH et alii ${ }^{33}$ ).

A avaliaçāo ecodopplercardiográfica tardia (média de 199 dias), realizada em sete ovinos, mostrou as válvulas da prótese com discreto espessamento, sem perda de sua mobilidade e suficiência.

Em quatro ovinos $(2,5,6,12)$, houve apenas aumento discreto do gradiente entre VD a TP (média $19,7 \mathrm{mmHg}$ ), o que comprovou a boa adaptaçāo hemodinâmica da prótese nesse período ${ }^{32}$. Estes gradientes foram menores do que os obtidos por SANTOS et alii ${ }^{46}$, onde os valores médios após o implante da prótese valvulada de pericárdio foi de $16 \mathrm{mmHg}$ aos três meses e $32,8 \mathrm{mmHg}$ aos seis meses de evolução.

O estudo hemodinâmico realizado em quatro ovinos (média 184 dias) mostrou calcificaçāo na parede livre da prótese, sem comprometer sua valva, em todos os casos.

Houve discreto aumento de gradiente VD-TP, variando entre $7 \mathrm{mmHg}$ e $27 \mathrm{mmHg}$ (média 22,3 $\mathrm{mmHg}$ ) através das anastomoses 32 . Ao contrário do experimento de SANTOS et alii ${ }^{46}$, com gradientes transvalvares variando entre $15 \mathrm{mmHg}$ e 25 $\mathrm{mmHg}$, a prótese tubular suína nāo apresentou gradiente, nesse período.

Estes resultados são compativeis com os achados de avaliação clínica tardia de homo e heteroenxertos implantados (STARK et alii ${ }^{50}$; KAY \& ROSS ${ }^{27}$ ).

A degeneração cálcica do tecido biológico é freqüente na evolução tardia destas próteses, processo que pode levar vários anos, sendo a disfunção decorrente de calcificação acelerada, mais freqüente em crianças e adolescentes. Sabe-se, porém, que os modelos experimentais são afetados da mesma maneira em períodos mais curtos (HARVERICH et alii ${ }^{19}$; BROWN et alii ${ }^{8}$; SANTOS et alii ${ }^{4}$ ).

$\mathrm{Na}$ procura de melhores resultados tardios, RADLEY-SMITH et alii ${ }^{40}$; ROSS \& SOMERVILE ${ }^{43}$, STARK et alii ${ }^{50}$ introduziram o uso de homoenxertos a fresco apenas mantidos em solução de antibióticos, observando queda na incidência de calcificação. 
MALUF, M. A.; VERDE, J. L.; LEAL, J. C.; CATANI, R.; GARCIA Jr., H. V.; THEVENARD, R.; CARVALHO, A. C.; ANDRADE, J. L.; ANDRADE, J. C. S.; BRAILE, D. M.; LEẢO, L. E. V.; BUFFOLO, E. - Reconstruçāo da valva pulmonar e via de saída do ventrículo direito, com prótese bivalvular e prótese tubular valvada de tronco pulmonar de porco: estudo experimental e aplicação clínica. Rev. Bras. Cir. Cardiovasc., 8(1):20-38, 1993.

Da mesma forma, os condutos sintéticos contendo heteroenxertos aórticos (suíno), que foram preservados em glutaraldeído, mostraram baixos índices de calcificação (BOWMAN et alii ${ }^{6}$; STARK et alii ${ }^{50}$; HECK et alii ${ }^{21}$; CIARAVELLA et alii ${ }^{9}$.

Com base nestes trabalhos e, especialmente, na experiência do IMC (BRAILE ${ }^{7}$ ) no tratamento de tecidos biológicos com glutaraldeído, adotou-se a mesma sistemática para o preparo da prótese tubular valvada. A calcificação acelerada prevista no modelo experimental em questăo atingiu apenas a parede da prótese, respeitando sua valva. Acredita-se seja ainda cedo para efetuar uma apreciação definitiva desta prótese. A aplicaçāo clínica já iniciada fornecerá, sem dúvida, valiosos dados para seu julgamento final.

Em relação ao implante da prótese tubular em pacientes, não houve dificuldades técnicas na realização das suturas ou sua acomodação na cavidade pericárdica, posicionada à esquerda da aorta (caso de $n^{2} 4$ ), ou à direita (caso de $n^{2} 5$ ), apesar de seu calibre $(18 \mathrm{~mm}$ e $16 \mathrm{~mm})$.

A boa evolução pós-operatória tardia (um ano) do caso de $n^{2} 4$, sem sinais de disfunção ou calcificação da prótese, mantendo gradientes menores de $20 \mathrm{mmHg}$, estimula a continuidade desta linha de pesquisa, ampliando suas indicaçōes.

Contudo, somente as experiências clínica e cirúrgica e, principalmente, a evoluçāo tardia permitirăo confirmar as vantagens potenciais do heteroenxerto pulmonar suíno na reconstituição da via de saída do ventrículo direito em relação à sua dura- bilidade, particularmente na manutenção da função valvular a longo prazo.

\section{CONCLUSŌES}

O desenvolvimento das próteses empregando tecido pulmonar suíno permitiu concluir:

A) Em relação à montagem:

Foi possível confeccionar dois modelos de próteses: bivalvular e tubular valvada utilizando dois segmentos de tronco pulmonar.

B) Em relaçāo à funçāo da prótese bivalvular "em telha":

Esta prótese permitiu reconstituir, adequadamente, a valva pulmonar e via de saída do ventrículo direito, sem deixar estenose residual significativa e sem provocar insuficiência pulmonar expressiva no período intra-operatório, avaliadas pelo ecodopplercardiograma e medidas hemodinâmicas.

C) Em relaçăo à prótese tubular valvada:

Esta prótese extracardíaca permitiu o desvio do fluxo sangüíneo do ventrículo direito para os pulmōes. Observaram-se baixos gradientes de pressão, ausência de insuficiência pulmonar e, quando ocorreu calcificação da parede da prótese, a valva foi poupada, mantendo a função, no período de tempo estudado (seis meses).

D) A prótese bivalvular em telha ou a prótese tubular valvada poderăo constituir-se em mais uma alternativa no tratamento cirúrgico da tétrade de Fallot e outras cardiopatias congênitas, devido aos bons resultados no início da experiência clínica. 
MALUF, M. A.; VERDE, J. L.; LEAL, J. C.; CATANI, R.; GARCIA Jr., H. V.; THEVENARD, R.; CARVALHO, A. C.; ANDRADE, J. L.; ANDRADE, J. C. S.; BRAILE, D. M.; LEĀO, L. E. V.; BUFFOLO, E. - Reconstruçāo da valva pulmonar e via de saída do ventrículo direito, com prótese bivalvular e prótese tubular valvada de tronco pulmonar de porco: estudo experimental e aplicaçáo clínica. Rev. Bras. Cir. Cardiovasc., 8(1):20-38, 1993.

\section{RBCCV 44205-196}

MALUF, M. A.; VERDE, J. L.; LEAL, J. C.; CATANI, R.; GARCIA Jr., H. V.; THEVENARD, R.; CARVALHO, A. C.; ANDRADE, J. L.; ANDRADE, J. C. S.; BRAILE, D. M.; LEĀO, L. E. V.; BUFFOLO, E. - Pulmonary valve and right ventricular oulet tract reconstruction with biovalvular prostheses and valved tubular prostheses of the pig pulmonary artery: experimental study and clinical application. Rev. Bras. Cir. Cardiovasc., 8(1):20-38, 1993.

ABSTRACT: Obstruction of the right ventricle outlet tract (RVOT) has been the object of arguments regarding its surgical correction, while there are different criteria for reconstruction. Thus two kinds of prostheses were developed from the pig pulmonary trunk (PT). 1) One with two valves of the pulmonary valve (PV), named bivalvular graft, and could be used for correction of Fallot with pulmonary ring hypoplasia. 2) The other, with a tubular form, containing the pig PV itself and named valved conduit, could be used in RVOT reconstruction for patients with pulmonary atresia (PA). These prostheses were tested in an experimental model: implant of the bivalvular graft was performed in 16 sheep with the aid of extracorporeal circulation (ECC). The surgical technique consisted of resection of the two valves of the PV and of the anterior wall of the infundibulum; this condition was similar to Fallot correction. Implant of the valvular conduit was carried out in 12 sheep, without ECC, by direct clamping of the RV infundibulum. The PT was then ligated, deviating blood flow through the conduit. Intraoperative hemodynamics and echodoppler evaluation of the bivalvular graft showed good PV competence and only 1 case of gradient higher than $10 \mathrm{mmHg}$. Because of frequent pulmonary hemorrhage followed by death due to ECC, this group was not evaluated in the postoperative period. Intraoperative hemodynamic measurements of the valvular conduit were carried out showing good valvular competence and gradient higher than $10 \mathrm{mmHg}$ in 3 cases. There was no operative mortality. Seven sheeps were followed-up during the late postoperative period with a control echodoppler on days 99 and 135 of follow-up. Gradients ranged from 9.85 to $49 \mathrm{mmHg}$ (mean $=19.7$ ). Four sheep underwent hemodynamic studies at six months of follow-up. There was a slight increase in the gradient between RV and PT (mean = $22.3 \mathrm{mmHg}$ ), no gradient being observed inside the conduit. Anatomopathological evaluation was performed. Clinical applications of the bivalvular prostheses was performed in 3 patients with tetralogy of Fallot and hypoplasia of the pulmonary ring (2 cases) and PV absent (1 case); they were 16,2 and 7 years old. The postoperative echodopplercardiogram showed gradients between 10 to $20 \mathrm{mmHg}$ and mild pulmonary valve insufficiency. Clinical application of the valvular conduit was performed in 2 patients: 1 with pulmonary atresia and ventricular septal defect (VSD), the other with corrected transposition of the great arteries, VSD and subpulmonary stenosis (10 and 6 years old, respectively). The postoperative echodopplercardiogram showed gradients between 15 to $18 \mathrm{mmHg}$. Although the results of the experiment may be considered acceptable, reconstruction of the RVOT with the newly developed prostheses, obviously requires to be tested over time to better evaluate their resistance to calcification, infection, obstruction and rupture.

DESCRIPTORS: heart valves, pulmonary, surgery; heart valves prostheses, biologic, surgery.

\section{REFERÊNCIAS BIBLIOGRÁFICAS}

1 AUSTEN, W. G.; GREENFIELD, L. J.; EBERT, P. A.; MORROW, A. G. - Experimental study of right ventricular function after surgical procedures involving the right ventricle and pulmonic valve. Ann. Surg., 155:606-613, 1962.

2 BAILEY, L. L.; PETRY, E. L.; DOROSHOW, R. W.; JACOBSON, J. G.; WAREHAN, E. E. - Biological reconstruction of right ventricular outflow tract. $J$. Thorac. Cardiovasc. Surg., 82:779-784, 1981.

3 BARBERO-MARCIAL, M.; RISO, A.; ATIK, E.; JATENE, A. D. - A technique for correction of truncus arterious types I and II without extra-cardiac conduits. J. Thorac. Cardiovasc. Surg., 99:364-369, 1990.

BARGER, A. C.; ROE, B. B.; RICHARDSON, G. S. Relation of valvular lesions and of exercise to

auricular pressure work tolerance, and to the developement of chronic, congestive failure in dogs. Am. J. Physiol., 169:384-399, 1952.

5 BINET, J. P.; LANGLOIS, J.; CARPENTIER, A.; LUCET, P.; MERCIER, J.; NOVAILLE, J.; HUALT, G. - Aortic heterograft of a pig valve on the pulmonary orifice. Presse Med., 76:5-9, 1968.

6

BRAILE, D. M. - Prótese valvular de pericárdio bovino: desenvolvimento e aplicação clínica em posiçāo mitral. Sāo Paulo, 1990. [Tese. Doutorado. Escola Paulista de Medicina].

8 BROWN, J. W.; HALPIN, M. P.; RESCORLA, F. J.; 
MALUF, M. A.; VERDE, J. L.; LEAL, J. C.; CATANI, R.; GARCIA Jr., H. V.; THEVENARD, R.; CARVALHO, A. C.; ANDRADE, J. L.; ANDRADE, J. C. S.; BRAILE, D. M.; LEĀO, L. E. V.; BUFFOLO, E. - Reconstruçāo da valva pulmonar e via de saída do ventrículo direito, com prótese bivalvular e prótese tubular valvada de tronco pulmonar de porco: estudo experimental e aplicaçāo clínica. Rev. Bras. Cir. Cardiovasc., 8(1):20-38, 1993.

VAN NATTA, B. W.; FIORE, A. C.; SHIPLEY, G. D.; BIZUNEH, M.; BILLS, R.; WALLER, B. - Externally stented polytetrafluoroethylene valved conduits for right heart reconstruction. J. Thorac. Cardiovasc. Surg., 90:883-891, 1985.

CIARAVELLA Jr., J. M.; Mc GOON, D. C.; DANIELSON, G. K.; WALLACE, R. B.; MAIR, D. D. - Experince with the extracardiac conduit. J. Thorac. Cardiovasc. Surg., 78:920-930, 1979.

COOLEY, D. A. \& HALLMAN, G. L. - Surgical treatment of congenital heart disease. Philadelphia, Lea \& Febiger, 1966. $185 \mathrm{p}$.

DONOVAN, T. J. - Experimental use of homologus vein graft to circunvent the pulmonic valves. Surg. Gynecol. Obstet., 90:204-208, 1950.

12 DURAN, C. M.; REVUELTA, J. M.; POMAR, J. L. - A new composite xenograft monocusp patch for reconstruction of the right ventricular outflow tract: a preliminary report. Cardiovasc. Dis., 7:58-562, 1980.

EBERT, P. A. - Second operation for pulmonary stenosis or insufficiency after repair of tetralogy of Fallot. Am. J. Cardiol., 50: 621-630, 1982.

14 EGUCHI, S. \& ASANO, K. - Homograft of pulmonary artery or ascending aorta with valve as a right ventricular outflow. J. Thorac. Cardiovasc. Surg., 56:413-420, 1968.

EGUCHI, S.; IRISAWA, T.; ASANO, $K$. - Use of valve retaining homograft and heterograft patch for reconstruction of right ventricular outflow tract. Ann. Thorac. Surg., 14:615-625, 1972.

ELLISON, R. G.; BROWN, W. J.; HAGUE, E. E.; HAMILTON, W. F. - Physiologic observations in experimental pulmonary insufficiency. J. Thorac. Cardiovasc. Surg., 30:633-641, 1955.

17 FUSTER, V.; McGOON, D. C.; KENNEDY, M. A. RITTER, D. C.; KIRKLIN, J. W. - Long term evaluation (12 to 22 years) of open heart surgery for tetralogy of Fallot. Am. J. Cardiol., 46:635-642, 1980.

GILBERT, J. W.; CORNELL, W. P.; COOPER, T. - An experimental study of pulmonary artery replacement. J. Thorac. Cardiovasc. Surg., 40:667-672, 1960.

HARVERICH, A.; OELERT, H.; MAATZ, W.; BORST, H. G. - Histopathological evaluation of woven and knitted Dacron grafts for right ventricular conduits: a comparative experimental study. Ann. Thorac. Surg., 37:404-411, 1984.

HAWE, A.; RASTELLI, G. C.; RITTER, D. G.; Du SHANE, J. W.; McGOON, D. C. - Management of the right ventricular outflow tract in severe tetralogy of Fallot. J. Thorac. Cardiovasc. Surg., 60:131. $143,1970$.
21 HECK, H. A.; SCHIEKEN, R. M.; DOTY, D. B. - Conduit repair for complex congenital disease: late follow up. J. Thorac. Cardiovasc. Surg., 75:806-814, 1978.

HOOTS, A. V. \& WATSON Jr., D. C. - Construction of an aortic homograft conduit for right ventricle to pulmonary artery continuity. Ann. Thorac. Surg., 48:731-732, 1989.

HORIUCHI, T.; ABE, T.; OKADA, Y.; KURIBAYASHI, R.; SUZUKI, Y.: ISHIZAWA, E. - Reconstruction of the main pulmonary artery with a valve bearing tube made of autologous pericardium. J. Thorac. Cardiovasc. Surg., 62:793-802, 1971.

24 HURWITT, E. S. - Experimental approach to problem of increasing blood supply to lungs: preliminary observation on use of plastics. Surg. Gynecol. Obst., 87:313-316, 1948.

5 IONESCU, M. I.; TANDON, A. P.; MACARTNEY, F. J. - Long term sequential hemodynamic evaluation of righ ventricular outflow tract reconstruction using a valve mechanism. Ann. Thorac. Surg., 27:426-434, 1979.

6 IONESCU, M. I. \& DEAC, R. C. - Fascia lata composite for right ventricular outflow tract and pulmonary artery reconstruction: surgical technique. Torax, 25:427-435, 1970.

7 KAY, J. H. \& ROSS, D. N. - Fifteen years experience with the aortic homograft: the conduit of choice for right ventricular outflow tract reconstruction. Ann. Thorac. Surg., 40:360-364, 1985.

8 KIRKLIN, J. W. \& BARRAT-BOYES, B. B. - Cardiac surgery. New York, John Wiley \& Sons, 1986. $1550 \mathrm{p}$.

9 KIRKLIN, J. W. \& KARP, R. B. - The tetralogy of Fallot from a surgical viewpoint. Philadelphia, W. B. Sounders, 1970. $131 \mathrm{p}$.

30 LECOMPTE, Y.; NEVEUX, J. Y.; LECA, F.; ZANNINI, L.; TU, T. V.; DUBOYS, Y.; JARREAU, M. M. Reconstruction of the pulmonary outflow tract without prosthetic conduit. J. Thorac. Cardiovasc. Surg., 84:727-733, 1982.

31 LILLEHEI, C. W.; COHEN, M.; WARDEN, H. E.; VARCO, R. L. - Complete anatomical correction of the tetralogy of Fallot defects: report of successful surgical case. Arch. Surg., 73:526-531, 1956.

2 MALUF, M. A. - Reconstituição da valva pulmonar e via de saída do ventrículo direito com prótese bivalvular ou prótese tubular valvada de artéria pulmonar suína: estudo experimental em ovinos. São Paulo, 1991. [Tese. Doutorado. Escola Paulista de Medicina].

Mc GRATH, L. B.; GONZALEZ-LAVIN, L.; GRAF. D. Pulmonary homograft implantation for ventricular outflow tract reconstruction: early phase results. Ann. Thorac. Surg., 45:273-277, 1988. 
MALUF, M. A.; VERDE, J. L.; LEAL, J. C.; CATANI, R.; GARCIA Jr., H. V.; THEVENARD, R.; CARVALHO, A. C.; ANDRADE, J. L.; ANDRADE, J. C. S.; BRAILE, D. M.; LEẢO, L. E. V.; BUFFOLO, E. - Reconstruçāo da valva pulmonar e via de saída do ventrículo direito, com prótese bivalvular e prótese tubular valvada de tronco pulmonar de porco: estudo experimental e aplicação clínica. Rev. Bras. Cir. Cardiovasc., 8(1):20-38, 1993.

MARCHAND, P. - The use of a cusp-bearing homograft for patch the outflow tract and pulmonary artery in Fallot's tetralogy and pulmonary valvular stenosis. Thorax, 22:497-509, 1967.

MEIER, M. A.; ELIAS, D. C.; NETO, W. J.; DOURADO, G.; RODRIGUES, N.; JAZBIK, W.; DE BIASE, A.; JAZBIK, A. P. - Reconstruçảo da saída do ventrículo direito na tetralogia de Fallot. Arq. Bras. Cardiol., 30 (Supl. 2):159, 1977. (Resumo).

MORAES, C. R. \& RODRIGUES, J. V. - Conduto valvulado de pericárdio bovino: relato de caso. Arq. Bras. Cardiol., 48:173-177, 1987.

OKU, H.; SHIROTANI, H.; ONISHI, H. - Two cusp plasty for the right ventricular outflow tract in complete repair of tetralogy of Fallot. Ann. Thorac. Surg., 45:9798, 1988.

OLIVEIRA, J. B.; SOUZA, L. C. B.; ARNONI, A. S.; SILVEIRA, F. S.; FIGUEIREDO, L. P.; CONFORTI, C. A.; BEMBOM, M. C. B.; JATENE, A. D.; PAULISTA, P. P. - Conduto valvulado: nova técnica. Arq. Bras. Cardiol., 46:401-406, 1986.

PACIFICO, A. D.; KIRKLIN, J. W.; BLACKSTONE, E. $\mathrm{H}$. - Surgical management of pulmonary stenosis in tetralogy of Fallot. J. Thorac. Cardiovasc. Surg., 74:382-395, 1977

RADLEY-SMITH, R.; AHMED, M.; YACOUB, M. - Late results of aortic homograft reconstruction of right ventricular outflow tract in infants and children. Thorax Chir. 23:455-459, 1975.

RASTELLI, G. C.; ONGLEY, P. A.; DAVIS, G. D.; KIRKLIN, J. W. - Surgical repair for pulmonary valve atresia with coronary-pulmonary artery fistula: report of case. Mayo Clin. Proc., 40:521-527, 1965.

ROSS, D. N. \& SOMERVILLE, J. - Correction of pulmonary atresia with a homograft aortic valve. Lancet., 2:1446-1447, 1966.

ROSS, D. N. \& SOMERVILLE, J. - Homograft reconstruction of right ventricular outflow tract in pulmonary atresia: late results. Br. Heart J., 38:316320, 1976.

ROWLATT, U. F.; RIMOLDI, H. J.; LEV, M. - The quantitative anatomy of the normal child's heart. Pediatr. Clin. Am., 10:499-506, 1963.

SABISTON, D. C.; CORNELL, W. P.; CRILEY, J. M.; NEILL, C. A.; ROSS, R. S.; BAHNSON, H. T. - The diagnosis and surgical correction of total obstruction of the right ventricle. J. Thorac. Cardiovasc. Surg., 48:577-587, 1964

SANTOS, J. L. V.; BRAILE, D. M.; SOARES, M. J. F.; RADE, W.; ROSSI, M. A.; THEVENARD, R.; SOU$Z A$, D.R.S. - Avaliação de tubo valvulado de pericárdio bovino em um modelo experimental animal. Rev. Bras. Cir. Cardiovasc., 5:16-25, 1990.

pericardial valved conduit. Rev. Latina Cardiol., 1:43-48, 1985.

48

SHAW, M. M.; ADAMS, W. E.; RASMUSSEN, R. A.; HARDINA, L. S.; ARONSON, H. G. - Experimental production of insufficiency and stenosis of the heart valves in dogs. J. Thoarc. Surg., 12:322-327, 1943.

49

SPICER, R. L.; BEHRENDT, D.; CROWLEY, D. C.; DICK, M.; ROCCHINI, A. P.; UZARK, K.; ROSENTHAL, A.; SLOAN, H. - Hepair of truncus arteriosus in neonates with the use of a valveless conduit. Circulation, 70 (Supl. 1):26-29, 1984.

STARK, J.; GANDHI, D.; DE LEVAL, M.; MACARTNEY, F.; TAYLOR, J. F. N. - Surgical treatment of persistent truncus arteriosus in the first year of life. Br. Heart J., 40:1280-1287, 1978.

51 SWAN, H.; CLEVELAND, H. C.; MUELLER, H.; BLOUNT, S. G. - Pulmonic valular stenosis: results and technique of open valvuloplasty. J. Thorac. Surg., 28:504-512, 1954.

52 TRUSLER, G. A.; IYENGAR, S. R.; MUSTARD, W. T. - Reconstruction of the pulmonary valve and outflow tract. J. Thorac. Cardiovasc. Surg., 65:245-251, 1973.

53 VANDERLEY NETO, J. W.; TORRES, L. D.; DE BIASE, A.; CAVALCANTE, C. C.: NOLASCO, R.; FERRO, H. C.; ALBUQUERQUE, P.; MOTA, M. A.; MARINHO, F. B.; DOURADO, G. - Avaliação hemodinâmica pós-operatória de via de saída do ventrículo direito. Arq. Bras. Cardiol., 39:209-215, 1982.

54 VERGINELLI, G.; BARBERO-MARCIAL, M.; PIERACCIANI, G.; MARTIN, J.; GOUVEIA, A. E.; EBAID, M.; ZERBINI, E. J. - Aneurisma do ventrículo direito após correçāo total de tetralogia de Fallot. Arq. Bras. Cardiol., 31:257-260, 1978.

WELDON, C. S.; ROWE, R. D.; GOTT, V. L. - Clinical experience with the use of aortic valve homografts for reconstruction of the pulmonary artery, pulmonary valve and outflow portion of the right ventricle. Circulation, 37 (Supl. 2):51-56, 1968.

56 WESSEL, H. U.; CUNNINGHAN, W. J.; PAUL, M. H.; BASTANIER, C. K.; MUSTER, A. J.; IDRISS, F. S. - Exercise performance in tetralogy of Fallot after intracardiac repair. J. Thorac. Cardiovasc. Surg., 80:582-593, 1980.

57 ZERBINI, E. J. - The surgical treatment of complex of Fallot: late results. J. Thorac. Cardiovasc. Surg., 58:158-177, 1969.

\section{Discussão}

DR. IVO A. NESRALLA

Porto Alegre (RS)

Inicialmente, gostaria de parabenizar os autores pela qualidade que o trabalho possui. Nem 
MALUF, M. A.; VERDE, J. L.; LEAL, J. C.; CATANI, R.; GARCIA Jr., H. V.; THEVENARD, R.; CARVALHO, A. C.; ANDRADE, J. L.; ANDRADE, J. C. S.; BRAILE, D. M.; LEĀO, L. E. V.; BUFFOLO, E. - Reconstruçäo da valva pulmonar e via de saída do ventrículo direito, com prótese bivalvular e prótese tubular valvada de tronco pulmonar de porco: estudo experimental e aplicação clínica. Rev. Bras. Cir. Cardiovasc., 8(1):20-38, 1993.

sempre a introduçāo de novas técnicas cirúrgicas é precedida de um estudo experimental que compreenda investigação imediata e a longo prazo em laboratório. Este estudo, ao apresentar tais características, pode ser considerado de valor inestimável e representa um modelo para outras pesquisas em cirurgia cardiovascular. Parece-nos, também, que o objetivo do estudo é bastante apropriado, considerando-se que o tratamento cirúrgico da obstrução à via de saída do ventrículo direito sempre foi motivo de controvérsias e fonte de engenhosas soluçōes. Consideramos que os aspectos importantes na terapêutica cirúrgica de malformaçōes contendo este tipo de obstrução sāo a restauração ou configuração de uma continuidade entre o ventrículo direito (ou ventrículo funcionalmente venoso) e a artéria pulmonar com gradiente de pressão ausente ou reduzido e que esta reconstituição mantenha esta característica por longo prazo. Isto porque a maioria dos pacientes a quem a cirurgia se destina pertence a um grupo etário muito jovem, com significativa perspectiva de ganho ponderal e de vida. A investigaçāo realizada mostra duas técnicas que podem ser utilizadas para restaurar a continuidade ventrículo direito-artéria pulmonar de maneira adequada. Como já citei, isto foi demonstrado de maneira elegante e metodologicamente correta. O estudo clínico que se segue à avaliação experimental serviu para ilustrar a factibilidade da técnica e sua adequaçāo em cirurgia de cardiopatias congênitas. Contudo, e esta talvez seja a única crítica ao trabalho, o uso em pacientes mostra um período relativamente curto de observação (até 10 meses), trazendo poucas informaçōes sobre a durabilidade da técnica de reconstruçāo da via de saída de ventrículo direito com artéria pulmonar suína. Como já se tem um maior conhecimento do desempenho tardio de diferentes técnicas de reconstruçāo utilizando enxertos compostos (tubos de Dacron com biopróteses ou próteses metálicas), enxertos heterólogos tubulares, valvados ou não, utilizando pericárdio bovino e, ainda, homoenxertos como a valva pulmonar ou aórtica, acredito que os resultados correspondentes a um maior tempo de acompanhamento com as técnicas propostas deve estar disponível para estudo comparativo e com vistas a recomendar seu emprego de rotina. Gostaria, novamente, de parabenizar os autores do trabalho, pela qualidade do mesmo e pela forma de apresentaçāo com que este chegou às nossas măos. Muito obrigado.

\section{DR. MALUF}

(Encerrando)

Obrigado, Dr. Nesralla, pelos seus comentários. Concordo com seu parecer em relação ao curto tempo de acompanhamento desta experiência clínica. De agora em diante, temos o compromisso do seguimento periódico dos pacientes que foram submetidos ao implante desta prótese, quando, entāo, poderemos fornecer informaçāo quanto à sua evoluçăo. Gostaria de ressaltar a importância de termos estes modelos de próteses com desempenho hemodinâmico satisfatório, porque, devido à ocorrência de calcificação tardia da prótese, nos permitiria a substituiçāo dos métodos de preservação ou do próprio tecido, mantendo a concepçāo original da sua montagem. 